\title{
Imperfect Competition, Information Heterogeneity, and Financial Contagion
}

\author{
Paolo Pasquariello \\ Ross School of Business, University of Michigan
}

\begin{abstract}
This study examines how heterogeneity of private information may induce financial contagion. Using a model of multi-asset trading in which the three main channels of contagion through financial linkages in the literature (correlated information, correlated liquidity, and portfolio rebalancing) are ruled out by construction, I show that financial contagion can still be an equilibrium outcome when speculators receive heterogeneous fundamental information. Risk-neutral speculators trade strategically across many assets to mask their information advantage about one asset. Asymmetric sharing of information among them prevents rational market makers from learning about their individual signals and trades with sufficient accuracy. Incorrect cross-inference about terminal payoffs and contagion ensue. When used to analyze the transmission of shocks across countries, my model suggests that the process of generation and disclosure of information in emerging markets may explain their vulnerability to financial contagion (JEL D82, G14, G15).
\end{abstract}

Many recent financial crises were initiated by episodes of "local" turmoil (e.g., Mexico in 1982 and 1994, Thailand in 1997, Russia in 1998, and Brazil in 1999) but ultimately spilled over to markets with little or no economic linkages to those initial shocks. ${ }^{1}$ More generally, a growing body of empirical evidence suggests that excess price comovement is a pervasive feature of many capital markets during both tranquil and uncertain times. Thus, it should not be surprising that financial contagion, the propagation of a shock to one security or market across fundamentally unrelated securities or markets, has become one of the most intriguing asset-pricing phenomena. At the same time, mutual funds have become a preferred investment vehicle in financial market

\footnotetext{
This article is based on the first chapter of my $\mathrm{PhD}$ dissertation. I benefited from the comments of two anonymous referees, Franklin Allen, Heitor Almeida, Michael Brennan, Menachem Brenner, Stephen Brown, Laurent Calvet, Qiang Dai, Joel Hasbrouck, Kose John, Jerry Kallberg, Pete Kyle, Holger Müller, Arun Muralidhar, Maureen O'Hara (the editor), Lasse Pedersen, Matthew Richardson, Alex Shapiro, Marti Subrahmanyam, Raghu Sundaram, George Wang, Robert Whitelaw, Jeffrey Wurgler, Kathy Yuan, and other participants in seminars at Rochester, Washington (St. Louis), Indiana, Wharton, Texas, Michigan, Board of Governors, LBS, Berkeley, Boston College, Dartmouth, HBS, NYU, Baruch College, the 2002 FMA Doctoral Symposium and Meetings, and the 2002 Lehman Brothers Fellowship Competition (whose dissertation grant I gratefully acknowledge). Any remaining errors are my own. Address correspondence to Paolo Pasquariello, Ross School of Business, University of Michigan, 701 Tappan Street, Suite E7602, Ann Arbor, MI 48109-1234, or e-mail:. ppasquar@bus.umich.edu.

${ }^{1}$ Table 1 in Kaminsky, Reinhart, and Vegh (2003) lists all financial crises with international repercussions between 1980 and 2000 .
}

(C) The Author 2006. Published by Oxford University Press on behalf of The Society for Financial Studies. All rights reserved. For permissions, please email: journals.permissions@oxfordjournals.org. 
worldwide. ${ }^{2}$ Accordingly, their role in those crises has been actively scrutinized by empirical research. ${ }^{3}$ Yet, theoretical analysis of the impact of the actions of sophisticated market participants on asset prices across fundamentally unrelated markets has only recently gained momentum.

Several alternative explanations of financial contagion have been proposed. Kaminsky, Reinhart, and Vegh (2003) surveyed the state of the literature. Existing theories can be broadly classified into two branches. To the first one belong models emphasizing the propagation of shocks through real linkages, such as trade or international business cycles. These models [e.g., Helpman and Razin (1978), Cole and Obstfeld (1991), Backus, Kehoe, and Kydland (1992), Baxter and Crucini (1993), Cass and Pavlova (2004), Pavlova and Rigobon (2004)] use macroeconomic theory to rationalize either spillover effects or high correlations in asset prices in the presence of low correlations of fundamentals [e.g., Bowden and Martin (1995)]. Empirical evidence on these channels is relatively abundant but often unsupportive [e.g., Kaminsky and Reinhart (2000a), Mody and Taylor (2002)]. Furthermore, their insight is arguably less pertinent in explaining why crises spread across at best weakly related regions like East Asia, Eastern Europe, and Latin America. Lastly, these models fail to explain why some episodes of financial turmoil (such as the currency devaluations in Turkey and Argentina in 2001) do not affect neighboring countries even in the presence of significant real regional linkages. ${ }^{4}$

Consequently, greater attention has been devoted to the second branch of the literature, made of models emphasizing the role of financial linkages in contagion. These models can in turn be grouped into three categories, depending on the specific mechanism generating excess comovement among the equilibrium prices of fundamentally unrelated financial markets. The first one, the correlated information channel, was originally introduced by King and Wadhwani (1990). It is based on the idea that information asymmetry leads uninformed traders to incorrect updating of beliefs on the payoffs of many assets following idiosyncratic shocks to a single asset. This argument, albeit intuitively appealing, is ultimately unsatisfactory, because it requires either that the terminal payoffs of the traded assets are related (hence excluding spillovers among such unrelated

\footnotetext{
${ }^{2}$ For instance, Bhattacharyya and Nanda (1999) reported that total equity holdings by mutual funds account for more than $16 \%$ of the value of US equities. Assets held by (mostly foreign) mutual funds in emerging markets represent smaller fractions of their market capitalization because of greater ownership concentration and lower turnover [Borensztein and Gelos (2000)].

${ }^{3}$ E.g., Brown, Goetzmann, and Park (1998), Eichengreen and Mathieson (1998), Kaminsky, Lyons, and Schmukler (2000, 2001), Disyatat and Gelos (2001), and Kim and Wei (2002).

${ }^{4}$ Kaminsky, Reinhart, and Vegh (2003, p. 52) referred to those circumstances as "contagion that never happened."
} 
regions as Asia and Latin America) or that the signals about them are related even if those payoffs are not (hence imposing some irrationality to the information-generation process). Along those lines, Fleming, Kirby, and Ostdiek (1998) and Kodres and Pritsker (2002) argued that the portfolio rebalancing activity of privately informed, price-taking investors-driven by risk aversion-may mislead the updating process of other, uninformed investors, thus eventually inducing financial contagion. However, mean-variance portfolio selection may not describe adequately the decision process of sophisticated investors, especially in developing markets. ${ }^{5}$ Finally, Calvo (1999), Kyle and Xiong (2001), and Yuan (2005) explored the consequences of insiders being financially constrained for the propagation of liquidity shocks across equilibrium prices. The resulting correlated liquidity channel of contagion is plausibly relevant in interpreting specific episodes such as the collapse of the hedge fund Long Term Capital Management (LTCM) and its implications for the world capital markets. ${ }^{6}$ Nonetheless, these models ignore that market participants hit by a liquidity shock might prefer to sell highly liquid assets, like those in developed exchanges, instead of their holdings in emerging markets.

Many of these theories assume that private information is shared symmetrically among price-taking insiders. Most financial markets are instead characterized by the presence of strategic traders endowed with diverse information. This is especially true in emerging markets, where the process of generation, acquisition, and disclosure of information is not as standardized as in more developed economies and where contagion has been observed more frequently. Information heterogeneity and imperfect competition among insiders represent a richer and more realistic view of a financial market, which so far has not been employed to investigate excess price comovement. The main objective of this article is to fill this gap.

For that purpose, I develop a three-date, two-period (short- and longrun) model of multi-asset trading based on Kyle (1985) and Caballé and Krishnan (1994), in which (i) markets are populated by informed, imperfectly competitive speculators, uninformed market makers (MMs), and liquidity traders; (ii) the terminal payoffs of the traded securities depend on idiosyncratic and systematic sources of risk; and (iii) trading occurs only at the end of the first period. As such, the model is best suited to capture the immediate, "fast and furious" propagation of shocks across unrelated markets that, according to Kaminsky, Reinhart, and Vegh

\footnotetext{
${ }^{5}$ For example, Nanda, Narayanan, and Warther (2000) and Das and Sundaram (2002) emphasized that compensation and principal-agent considerations are more important to understand observed investment policies of professional money managers; Disyatat and Gelos (2001) showed that mean-variance optimization fails to explain changes in portfolio weights for more than 600 emerging market mutual funds between January 1996 and December 2000.

${ }^{6}$ For an analysis of the LTCM debacle, see Edwards (1999).
} 
(2003), takes place over a matter of hours or days during most episodes of financial contagion. Motivated by the above discussion, I further assume that (iv) the speculators receive separate signals of future realizations of those local and common factors, to control for the correlated information channel of contagion; (v) the speculators are risk-neutral, to control for the portfolio rebalancing channel of contagion; and (vi) the speculators do not face any borrowing, short-selling, or wealth constraints, as well as noise trading is independent across assets, to control for the correlated liquidity channel of contagion. In this setting, I show that excess comovement may still represent an equilibrium outcome, yet only if those speculators receive heterogeneous private information about the liquidation values of the assets and strategically trade on it.

This result constitutes the main contribution and empirical implication of the article. The intuition for it is as follows. Assume a three-country economy in which two peripheral (e.g., emerging) markets are fundamentally unrelated to each other but have some macroeconomic exposure to a third, core (e.g., developed) market. For instance, we may think of the two peripheral countries as Thailand and Brazil and of the core country as Germany. In this setting, the uninformed MMs may use the observed demand for one country's assets to learn about the terminal payoffs of other countries' assets. I label this learning activity cross-inference. Assume now that the speculators receive private information about a future negative idiosyncratic shock (e.g., a shift in the stance of monetary policy) for the terminal asset values of Thailand. In response to this new information, risk-neutral speculators could choose to sell Thai assets alone. Yet, this trading activity would dissipate at least part of their informational advantage and so reduce their expected profits. In the presence of dealers' cross-inference, the speculators instead optimally trade cautiously and strategically across markets, rather than massively and exclusively in Thailand, to minimize such dissipation of information. Specifically, in this example, not only do they sell Thai assets but also they buy German assets and sell Brazilian assets. They do so to lead the MMs to believe that their trading activity is driven by new systematic information (rather than local shocks), that is, to attenuate the ensuing downward revision of market prices in Thailand.

In my model, MMs are rational. Hence, they account for speculators' potential strategic trading activity in the order flow when setting equilibrium prices. Their ability to do so accurately determines whether contagion occurs in this stylized economy. Speculators are imperfectly competitive, thus have an incentive to act noncooperatively to exploit their perceived informational edge. When speculators are homogeneously informed, they compete more aggressively to reap the benefits of their private signals. This competition makes the aggregate order flow informative enough for dealers to learn that the observed cross-market trading 
activity (sell Thailand, buy Germany, and sell Brazil) is due to a negative idiosyncratic shock to Thailand alone. In the resulting equilibrium, only asset prices in Thailand drop. Heterogeneity of private signals induces each speculator to a more cautious, quasi-monopolistic behavior, because part of his informational advantage is known exclusively to him. The ensuing cross-border trading activity leads the dealers to incorrect crossinference about the origins of the shocks driving the observed order flow. Consequently, financial contagion arises in equilibrium: not only do asset prices in Thailand drop but asset prices in Germany increase and, more interestingly, asset prices in Brazil decline as well, although Thailand and Brazil are fundamentally unrelated.

Consistent with this argument, Kallberg and Pasquariello (2004) found that a significant portion of excess comovement within the US stock market can be explained by the dispersion of analysts' earning forecasts [a proxy for information heterogeneity suggested by Diether, Malloy, and Scherbina (2002)] even after controlling for market volatility. I further show that greater (lower) intensity of information heterogeneity within a market as well as greater (lower) participation of sophisticated investors induce more (less) incorrect inference about its liquidation values, hence making that market more (less) vulnerable to external idiosyncratic shocks. This implication may help explain the stylized observation [reported, e.g., in Kaminsky, Reinhart, and Vegh (2003)] that financial crises hitting large or small countries often have little or no international repercussions (despite the occurrence of cross-border capital flows) and only on occasion spread rapidly and virulently across the world capital markets.

Current empirical research [e.g., Kaminsky and Reinhart (2000b)] also emphasizes the role played by financial centers for the propagation of shocks across unrelated peripheral markets. The example above illustrates a novel mechanism through which such propagation may take place. Conversely, autarkic economies are seldom deemed likely to experience contagion effects [Kaminsky, Reinhart, and Vegh (2003)]. Accordingly, in my setting, I demonstrate that excess price comovement is more likely and of greater magnitude within and among more economically interconnected regions and markets, because the latter induces greater (and possibly incorrect) cross-inference by the uninformed MMs. ${ }^{7}$ This claim is supported by numerous studies of price comovement during contagious financial crises [Kaminsky and Schmukler (2002), Rigobon (2002), Bekaert, Harvey, and Ng (2005)]. These results have several policy implications as well. In particular, they suggest that the process of economic and financial integration and persistent asymmetric

\footnotetext{
${ }^{7}$ Conversely, I also show that, in my model, no contagion takes place in the less realistic setting in which all economies are autarkic. Yet, as the three-country example illustrates, this is not equivalent to saying that, in our model, excess comovement may occur only among fundamentally related assets. I defer further discussion of this issue to Sections 2 and 3.
} 
information sharing among sophisticated traders may explain why financial contagion has been occurring with greater frequency and magnitude in emerging markets. Therefore, the adoption of rigorous and uniform rules for the dissemination of corporate and macroeconomic information may strengthen their ability to withstand or avoid international spillover effects.

The article is organized as follows. In Section 1, I outline the basic economy and derive its equilibrium. In Section 2, I define financial contagion, establish the main results of this study, and provide intuition for the channels of transmission of shocks across fundamentally unrelated markets with the help of a numerical example. In Section 3, I link equilibrium excess comovement to fundamental properties of the underlying economy. In Section 4, I conclude. All proofs are in Appendix A.

\section{The Model}

\subsection{Structure and notation}

The model is based on Kyle (1985) and Caballé and Krishnan (1994). Consider a three-date, two-period economy consisting of $N$ risky assets and a riskless asset (the numeraire) whose gross return is normalized to one. Trading occurs only at the end of the first period $(t=1)$. At the end of the second period $(t=2)$, the payoffs of the risky assets, a $N \times 1$ multivariate normally distributed (MND) random vector $v$ with mean $\bar{v}$ and nonsingular covariance matrix $\Sigma_{v}$, are realized. When $\Sigma_{v}$ is either nondiagonal or block-diagonal (see Definition A1 in Appendix A), either some of the $N$ assets or some assets in any subset (block) are fundamentally correlated to each other. We model this correlation by assuming that $v$ is characterized by the following linear factor structure:

$$
v=u+\beta \vartheta
$$

where $u$ is an $N \times 1$ random vector of idiosyncratic shocks, $\vartheta$ is an $F \times 1$ random vector of systematic sources of risk, and $\beta$ is an $N \times F$ matrix of factor loadings. We assume that $u$ and $\vartheta$ are MND with means $\bar{u}$ and $\bar{\vartheta}$ and (diagonal and nonsingular) covariance matrices $\Sigma_{u}$ and $\Sigma_{\vartheta}$. Consequently, $\bar{v}=\bar{u}+\beta \bar{\vartheta}$ and $\Sigma_{v}=\Sigma_{u}+\beta \Sigma_{\vartheta} \beta^{\prime}$ are also nonsingular and nondiagonal. ${ }^{8}$

The structure of the economy in Equation (1) is general enough to encompass the broadest possible classes of assets and fundamental comovement (or lack thereof) among them. In this article, I concentrate

\footnotetext{
${ }^{8}$ Obviously, the latter is true unless $\beta=O$, where $O$ is a zero matrix. The matrix $\left[\Sigma_{u}+\beta \Sigma_{\vartheta} \beta^{\prime}\right]^{-1}$ always exists for any $N \times F$ matrix $\beta$ if both $\Sigma_{u}$ and $\Sigma_{\vartheta}$ are nonsingular [e.g., Maddala (1987, p. 446)]. Hence, the nonsingularity of $\Sigma_{v}$ does not impose any restriction on the factor loadings $\beta$.
} 
on the transmission of shocks across economically unrelated markets. For that purpose, I assume that (i) any risky security $n$ represents country $n$ 's all-inclusive market index and (ii) the random vectors $u$ and $\vartheta$ constitute the macroeconomic determinants of those countries' long-run $(t=2)$ asset values $v$. I then interpret $u$ as future realizations of domestic risk factors (e.g., local fiscal and monetary policies, tax regimes, political events) and $\vartheta$ as future realizations of global sources of risk, such as world (or regional) business cycles, commodity prices, or terms of trade. ${ }^{9}$

To gain further insight into this interpretation, I construct a simple example along the lines of Kodres and Pritsker (2002). Specifically, I assume that there are three countries in the economy and that, as in Equation (1), the liquidation values of the indices there traded depend on $u$ and $\vartheta$ by way of the following expressions:

$$
\begin{aligned}
& v(1)=u(1)+\vartheta(1) \\
& v(2)=u(2)+0.5 \vartheta(1)+0.5 \vartheta(2) \\
& v(3)=u(3)+\vartheta(2) .
\end{aligned}
$$

The two "peripheral" countries, 1 and 3 , are fundamentally unrelated (i.e., $\operatorname{cov}[v(1), v(3)]=0$ ) but share an exposure to the "core" market 2 through the systematic factors $\vartheta(1)$ and $\vartheta(2)$, respectively. I use a parsimonious baseline parametrization of Equation (2), reported in Appendix B [Equation (B1)]. In the resulting economy, we can think of country 2, with the lowest fundamental variance and exposure to both $\vartheta(1)$ and $\vartheta(2)$, as a developed, globalized market, and of countries 1 and 3 as developing (e.g., emerging) and economically unrelated markets. The main objective of this article is to describe a novel mechanism by which, for instance, shocks to country 1 may propagate to the equilibrium asset prices of country 3 .

\subsection{Market participants and information}

I consider a market with risk-neutral traders: perfectly competitive MMs, $K$ privately informed speculators, and liquidity traders. Risk-neutrality rules out by construction the portfolio rebalancing channel of contagion of Kodres and Pritsker (2002) described in the Introduction. Speculators do not observe current prices or trades. MMs do not receive any private information but observe the aggregate order flow from all market participants. All traders know the structure of the economy and the decision process leading to order flow and prices. Yet, the future

\footnotetext{
${ }^{9}$ For instance, in a recent study, Bekaert, Harvey, and $\mathrm{Ng}$ (2005) found that both country-specific information and regional and global fundamentals are important for the stock returns of developed and developing economies. Yet, according to Bowden and Martin (1995), international stock markets display greater "coherence" than do the corresponding economies.
} 
realizations of both asset-specific $(u)$ and common $(\vartheta)$ sources of risk are unobservable until time $t=2$.

At time $t=0$, there is no information asymmetry about $v$, and the prices of the risky assets are given by the unconditional means of their terminal payoffs: $P_{0}=\bar{v}$. Sometime between $t=0$ and $t=1$, each speculator receives two sets of private and noisy signals $S_{u k}$ and $S_{\vartheta k}$ of the future realizations of $u$ and $\vartheta$. In the spirit of Admati (1985), it is assumed that those signals take the form $S_{u k}=u+\varepsilon_{u k}$ and $S_{\vartheta k}=\vartheta+\varepsilon_{\vartheta k}$, where $\varepsilon_{u k} \sim M N D\left(\underline{0}, \Sigma_{\varepsilon_{u k}}\right), \varepsilon_{\vartheta k} \sim M N D\left(\underline{0}, \Sigma_{\varepsilon_{\vartheta k}}\right)$, and $\underline{0}$ is a zero vector. I further impose that $u, \vartheta$, and all $\varepsilon_{u k}$ and $\varepsilon_{\vartheta k}$ are mutually independent, that $\Sigma_{\varepsilon_{u k}}=\Sigma_{\varepsilon_{u}}$ and $\Sigma_{\varepsilon_{\vartheta k}}=\Sigma_{\varepsilon_{\vartheta}}$ (i.e., that the precision of each signal is identical across insiders), and that $\Sigma_{\varepsilon_{u}}$ and $\Sigma_{\varepsilon_{\vartheta}}$ are diagonal. These assumptions imply that each speculator's expectation of $v$ at $t=1$, before trading with the MMs, is given by

$$
E\left(v \mid S_{u k}, S_{\vartheta k}\right) \equiv E_{1}^{k}(v)=\bar{v}+\Sigma_{u} \Sigma_{S_{u}}^{-1}\left(S_{u k}-\bar{u}\right)+\beta \Sigma_{\vartheta} \Sigma_{S_{\vartheta}}^{-1}\left(S_{\vartheta k}-\bar{\vartheta}\right),
$$

where $\Sigma_{S_{u}}=\Sigma_{u}+\Sigma_{\varepsilon_{u}}$ and $\Sigma_{S_{\vartheta}}=\Sigma_{\vartheta}+\Sigma_{\varepsilon_{\vartheta}}$. According to Equation (3), speculators' inference about the nature of any future macroeconomic shock (local versus widespread) is consistent with the underlying economy of Equation (1). Hence, the correlated information channel of contagion of King and Wadhwani (1990) described in the Introduction is ruled out by construction. ${ }^{10}$

I define the informational advantage of each speculator about $v$ with respect to the uninformed traders by the random vector $\delta_{k}=E_{1}^{k}(v)-$ $\bar{v} \sim \operatorname{MND}\left(\underline{0}, \Sigma_{\delta}\right)$, where

$$
\operatorname{var}\left(\delta_{k}\right) \equiv \Sigma_{\delta}=\Sigma_{u} \Sigma_{S_{u}}^{-1} \Sigma_{u}+\beta \Sigma_{\vartheta} \Sigma_{S_{\vartheta}}^{-1} \Sigma_{\vartheta} \beta^{\prime}
$$

is nonsingular. The above assumptions also imply that, for any two $\delta_{k}$ and $\delta_{i}$,

$$
\operatorname{cov}\left(\delta_{k}, \delta_{i}\right) \equiv \Sigma_{c}=\Sigma_{u} \Sigma_{S_{u}}^{-1} \Sigma_{u} \Sigma_{S_{u}}^{-1} \Sigma_{u}+\beta \Sigma_{\vartheta} \Sigma_{S_{\vartheta}}^{-1} \Sigma_{\vartheta} \Sigma_{S_{\vartheta}}^{-1} \Sigma_{\vartheta} \beta^{\prime},
$$

\footnotetext{
${ }^{10}$ Indeed, both the economy of Equation (1) and the corresponding signals $S_{u k}$ and $S_{\vartheta k}$ prevent the speculators from drawing "incorrect" inference about the origins of shocks to $v$ from the signals they receive. For instance, assume a covariance matrix $\Sigma_{v}$ identical to that implied by Equation (2) and Appendix B and that speculators are given just one set of signals about $v$, that is, $S_{v k}=S_{u k}+\beta S_{\vartheta k}$ such that $\Sigma_{S_{v}}=\Sigma_{S_{u}}+\beta \Sigma_{S_{u}} \beta^{\prime}$. Equation (3) then implies that those speculators would erroneously infer comovement between indexes 1 and 3 although countries 1 and 3 are fundamentally unrelated: $E_{1}^{k}(v)=\bar{v}+\Sigma_{v} \Sigma_{S_{v}}^{-1}\left(S_{v k}-\bar{v}\right)$ and, for example, $\frac{\partial E_{1}^{k}[v(3)]}{\partial v(1)}=\Sigma_{v} \Sigma_{S_{v}}^{-1}(3,1)=-0.019$ although $\operatorname{cov}[v(1), v(3)]=0$. Our assumptions instead imply "correct" inference by the speculators about the source of shocks to $v: \frac{\partial E_{1}^{k}[v(3)]}{\partial u(1)}=\Sigma_{u} \Sigma_{S_{u}}^{-1}(3,1)=0$ and $\frac{\partial E_{1}^{k}[v(3)]}{\partial \vartheta(1)}=\beta \Sigma_{\vartheta} \Sigma_{S_{\vartheta}}^{-1}(3,1)=0$.
} 
a symmetric positive definite (SPD) matrix. ${ }^{11}$ Therefore, $E_{1}^{k}\left(\delta_{i}\right)=$ $\Sigma_{c} \Sigma_{\delta}^{-1} \delta_{k}$. In this setting, speculators receive the same or similar information if $S_{u k}=S_{u}$ and $S_{\vartheta k}=S_{\vartheta}$, so $\Sigma_{c}=\Sigma_{\delta}$, or if $S_{u k} \neq S_{u i}$ and $S_{\vartheta k} \neq S_{\vartheta i}$ but $\Sigma_{c}=\rho \Sigma_{\delta}$ (with $\rho \in(0,1)$ ). ${ }^{12}$ Conversely, the more $\Sigma_{c} \neq \rho \Sigma_{\delta}$, the more heterogeneous is speculators' information. For the remainder of the article, I refer to the former as information homogeneity $\left(\Sigma_{c}=\rho \Sigma_{\delta}\right)$ and to the latter as information heterogeneity $\left(\Sigma_{c} \neq \rho \Sigma_{\delta}\right)$ among speculators. We can interpret such heterogeneity as arising from the use of diverse sources to learn about the factors affecting $v$. Significant and persistent differences in private information among traders are common in most financial markets, especially the ones of emerging economies, where the process of generation and acquisition of information is not as standardized as in more developed countries. ${ }^{13}$

\subsection{Market participants and trading}

At $t=1$, both speculators and liquidity traders submit their orders to the MMs, before the price vector $P_{1}$ has been set. Liquidity traders are assumed to generate a vector of random demands $z$, independent from any $\delta_{k}$ and MND with mean $\bar{z}$ and nonsingular covariance matrix $\Sigma_{z}$. To control for the liquidity channel of asymmetric contagion of Calvo (1999), Kyle and Xiong (2001), and Yuan (2005) described in the Introduction, I impose that $\Sigma_{z}$ is also diagonal and that speculators do not face borrowing, short-selling, or wealth constraints.

It is a stylized fact about speculative markets (especially emerging markets) that better-informed traders (especially if large enough) use their informational advantage to influence prices, instead of taking them as given. The latter, Grinblatt and Ross (1985) argued, would be "irrational" because prices respond to their actions. Here, I posit that the $K$ speculators are imperfectly competitive: in equilibrium, they correctly anticipate the pricing rule and use this knowledge in formulating their orders, as in Kyle (1989). At $t=0$, each speculator holds an amount $N A V_{0 k}$ of the riskless asset. Hence, his optimal demand for risky assets, $X_{k}$, maximizes the expected value of the following utility function $U_{k}$ of the net asset value (NAV) of his portfolio at $t=2$ :

\footnotetext{
${ }^{11}$ See Definition A2 in Appendix A.

12 The parametrization of Equation (2) in Appendix B only allows for the former. The latter is true when all matrices $\Sigma_{u}, \Sigma_{\varepsilon_{u}}, \Sigma_{\vartheta}$, and $\Sigma_{\varepsilon_{\vartheta}}$ are multiples of the corresponding identity matrix $I$ such that $\Sigma_{S_{u}}^{-1} \Sigma_{u}=\rho I$ and $\Sigma_{S_{\vartheta}}^{-1} \Sigma_{\vartheta}=\rho I$. In that case, each speculator expects the information endowments of the others to be a fraction of (thus perfectly correlated to) his own: $E_{1}^{k}\left(\delta_{i}\right)=\rho \delta_{k}$; moreover, the higher is $\rho$, the closer is $\operatorname{cov}\left(\delta_{k}, \delta_{i}\right)$ to $\operatorname{var}\left(\delta_{k}\right)$ (and $E_{1}^{k}\left(\delta_{i}\right)$ to $\delta_{k}$ ), hence the greater is the similarity between $\delta_{k}$ and $\delta_{i}$.

${ }^{13}$ Furthermore, there is much anecdotal and empirical evidence of asymmetric information in the markets of developing economies although a controversy persists on whether domestic or international investors would have the informational edge. A partial list of studies on this topic includes Chuhan (1992), Frankel and Schmukler (1996), Brennan and Cao (1997), Claessens, Djankov, and Lang (2000), Seasholes (2000), and Froot, O'Connell, and Seasholes (2001).
} 


$$
U_{k}=U\left(N A V_{2 k}\right)=N A V_{0 k}+X_{k}^{\prime}\left(v-P_{1}\right),
$$

where $N A V_{2 k}$ is announced at the end of the second period, after $v$ is realized. $^{14}$

\subsection{Equilibrium}

In this economy, the MMs face a quantity-based signal extraction problem: At $t=1$, they observe only the aggregate order flow for all securities $\omega_{1}=\sum_{i=1}^{K} X_{i}+z$ and, with the information extracted from it, set the market-clearing price vector $P_{1}=P_{1}\left(\omega_{1}\right) .{ }^{15}$ Because $X_{k}=$ arg $\max E_{1}^{k}\left(U_{k}\right)$, we can think of the speculators' optimal trading strategies as functions of the realizations of $\delta_{k}: X_{k}=X_{k}\left(\delta_{k}\right)$. I now show that a linear equilibrium for this economy exists. I use the following standard definition of equilibrium [Kyle (1985), Caballé and Krishnan (1994)].

Definition 1. A Bayesian Nash equilibrium is a set of $K+1$ vector functions $X_{1}(\cdot), \ldots, X_{K}(\cdot)$ and $P_{1}(\cdot)$, such that the conditions below hold:

1. Utility maximization:

$$
\begin{aligned}
& E_{1}^{k}\left(U_{k}\left\{X_{k}\left(\delta_{k}\right), P_{1}\left[\sum_{i=1}^{K} X_{i}\left(\delta_{i}\right)+z\right]\right\}\right) \\
& \quad \geq E_{1}^{k}\left(U _ { k } \left\{Y_{k}\left(\delta_{k}\right), P_{1}\left[Y_{k}\left(\delta_{k}\right)+\sum_{\substack{i=1 \\
i \neq k}}^{K}\right.\right.\right. \\
& \left.\left.\left.\quad X_{i}\left(\delta_{i}\right)+z\right]\right\}\right),
\end{aligned}
$$

for any alternative trading strategy $Y_{k}(\cdot)$ and for all $k=1, \ldots, K$;

2. Semi-strong market efficiency:

$$
P_{1}\left(\omega_{1}\right)=E\left(v \mid \omega_{1}\right)
$$

\footnotetext{
${ }^{14}$ In a previous version, I allowed each speculator $k$ to hold an inventory $e_{k}$ of risky securities at $t=0$, to possess an information advantage about it and to extract utility from the intermediate NAV of his portfolio $\left(N A V_{1 k}\right)$ as follows: $U_{k}=\gamma U\left(N A V_{1 k}\right)+(1-\gamma) U\left(N A V_{2 k}\right)$, where $N A V_{1 k}=$ $N A V_{0 k}+e_{k}^{\prime}\left(P_{1}-P_{0}\right)+X_{k}^{\prime}\left(P_{1}-P_{1}\right)$, as in Bhattacharyya and Nanda (1999). In this setting, I showed that: (i) a portion of the speculators' demand is uninformative, hence consenting trading in equilibrium even in the absence of liquidity shocks $z$ [similarly to Diamond and Verrecchia (1981)] and (ii) speculators" "impatience" $(\gamma>0)$ leads to financial contagion in the presence of endowment shocks (e.g., early redemptions by mutual fund investors), regardless of their degree of information heterogeneity. Recent studies by Connolly and Wang (2000) and Kaminsky, Lyons, and Schmukler (2000, 2001) provide empirical support for this propagation channel.

${ }^{15}$ According to Calvo and Mendoza (2000), this modeling approach is especially relevant for emerging economies, in view of the short history of prices available for their domestic capital markets under financial integration. In addition, MMs in emerging over-the-counter markets normally provide quotes for multiple securities. However, even in organized exchanges, specialists may communicate to learn about each other's order flow. Because the MMs do not possess private information and hold their positions until liquidation (at $t=2$ ), we can also think of them as uninformed long-term speculators, as in Froot, Scharfstein, and Stein (1992).
} 
Equation (7) requires that speculators' market orders $X_{k}$ be optimal, given their information, before the MMs choose $P_{1}$. Equation (8) is the result of competition among identical dealers driving to zero their expected long-term profits in each market, conditional on the signal they observe $\left(\omega_{1}\right)$, that is, such that $\omega_{1}(n)\left[E\left(v(n) \mid \omega_{1}\right)-P_{1}(n)\right]=0$ for each $n$. The following proposition characterizes a symmetric linear equilibrium for this economy, similarly to Caballé and Krishnan (1994, Proposition 3.1).

Proposition 1. There always exists a linear equilibrium given by the price function

$$
P_{1}=P_{0}+\frac{\sqrt{K}}{2} \Lambda\left(\omega_{1}-\bar{z}\right)=P_{0}+H \sum_{i=1}^{K} \delta_{i}+\frac{\sqrt{K}}{2} \Lambda(z-\bar{z})
$$

and by each speculator's demand strategy

$$
X_{k}=C \delta_{k},
$$

where $\Lambda=\Sigma_{z}^{-1 / 2} \Psi^{1 / 2} \Sigma_{z}^{-1 / 2}$ is a SPD matrix, $\Psi=\Sigma_{z}^{1 / 2} \Gamma \Sigma_{z}^{1 / 2}$, $\Gamma$ is a SPD matrix defined in Appendix $A$ [Equation (A3) ], $C=\frac{2}{\sqrt{K}} \Lambda^{-1} H$, and $H=\left[2 I+(K-1) \Sigma_{c} \Sigma_{\delta}^{-1}\right]^{-1} \cdot{ }^{16}$

Remark 1. If there is only one speculator $(K=1)$, then $\Lambda=\Sigma_{z}^{-1 / 2}$ $\left(\Sigma_{z}^{1 / 2} \Sigma_{\delta} \Sigma_{z}^{1 / 2}\right)^{1 / 2} \Sigma_{z}^{-1 / 2}$ and $H=\frac{1}{2} I$; if there are many homogeneously informed speculators $\left(K>1\right.$ and $\left.\Sigma_{c}=\rho \Sigma_{\delta}\right)$, then $\Lambda=\frac{2}{2+\rho(K-1)}$ $\Sigma_{z}^{-1 / 2}\left(\Sigma_{z}^{1 / 2} \Sigma_{\delta} \Sigma_{z}^{1 / 2}\right)^{1 / 2} \Sigma_{z}^{-1 / 2}$ and $H=\frac{1}{2+\rho(K-1)} I$; and if there are many heterogeneously informed speculators $\left(K>1\right.$ and $\left.\Sigma_{c} \neq \rho \Sigma_{\delta}\right)$, then the matrix $H$ is nondiagonal.

The optimal trading strategy of each speculator depends on the information he or she receives about $v$. The MMs do not know how much of the order flow is due to speculators' informed trading. Thus, $P_{1}$ depends only on the portion of $\omega_{1}$ that the MMs expect to be informative about $v$. The existence of noise trading is an important ingredient of the model: as emphasized by Admati (1985), a nonsingular $\Sigma_{z}$ effectively provides camouflage for informed trades, because it prevents $\omega_{1}$ from being a sufficient statistic for any combination of speculators' private signals of $v$. Furthermore, the imperfectly competitive speculators are aware of

\footnotetext{
${ }^{16}$ In addition, Caballe and Krishnan (1994) show that this equilibrium is the unique linear equilibrium if either $K=1$ (there is a single speculator) or $\Sigma_{z}=\sigma_{z}^{2} I$ (noise trading has identical variance and is uncorrelated across assets). In the latter case, $\Lambda=\frac{1}{\sigma_{z}} \Gamma^{1 / 2}$. For ease of interpretation, when calibrating the equilibrium of Proposition 1 in our numerical examples [e.g., Equation (2)], I therefore impose that $\Sigma_{z}=I$ [see Appendix B, Equation (B2)].
} 
the impact of their trades on $P_{1}$ (through $\Lambda$ ). Thus, despite being riskneutral, they trade cautiously $\left(\left|X_{k}(n)\right|<\infty\right)$ to prevent $\omega_{1}$ from fully dissipating their informational advantage. Hence, the expressions in Equations (9) and (10) represent a noisy rational expectations equilibrium. ${ }^{17}$ The matrix $\frac{2}{\sqrt{K}} \Lambda^{-1}$ measures the depth of this multi-asset market. The equilibrium market depth reflects MMs' attempt to be compensated for the losses they anticipate from trading with speculators, because it affects their profits from liquidity trading. Multiple, homogeneously informed speculators, acting noncooperatively, have an incentive to trade more aggressively than a monopolist speculator would. ${ }^{18}$ This "quasi-competitive" behavior makes the aggregate order flow $\left(\omega_{1}\right)$ more revealing about $v$. Hence, the MMs, fearing less adverse selection, reduce their compensation for it by increasing each market's liquidity. Heterogeneously informed speculators compete less aggressively with each other. When information is less correlated, each speculator has some monopoly on his private signal because part of it is known exclusively to him. This "quasimonopolistic" behavior makes $\omega_{1}$ less informative about each individual signal and trading activity. Accordingly, the equilibrium market depth declines. A monopolist speculator is the least aggressive: unthreatened by informed competition, he can exploit fully his private signals by trading most cautiously to preserve his information advantage. The resulting $\omega_{1}$ is the least informative about $v$, and the equilibrium market depth the lowest. ${ }^{19}$

The MMs discount their knowledge of the speculators' behavior into $P_{1}$, whereas the speculators discount their knowledge of the process by which MMs set $P_{1}$ into $X_{k}$. Consequently, although $\operatorname{var}\left(X_{k}\right)=\frac{1}{K} \Sigma_{z}$, the unconditional variance of $P_{1}$, given by

$$
\operatorname{var}\left(P_{1}\right)=K H \Sigma_{\delta},
$$

is not a function of $\Sigma_{z}$, as in Kyle (1985). More liquidity trading offers more hiding opportunities to speculators, brings forth more aggressive informative trading, and eventually does not destabilize prices in

\footnotetext{
${ }^{17}$ In contrast, in the Gaussian setting with perfect competition of Admati (1985), where prices aggregate information across risk-averse traders, all private information is fully revealed when their risk aversion wanes.

${ }^{18}$ Remark 1 in fact implies that $\left|\sum_{i=1}^{K} X_{i}\right|>\left|X_{K=1}\right|$ when $\Sigma_{c}=\rho \Sigma_{\delta}$.

${ }^{19}$ It can in fact be shown that, for each $n=1, \ldots, N, \quad \Sigma_{z}^{-1 / 2}\left(\Sigma_{z}^{1 / 2} \Sigma_{\delta} \Sigma_{z}^{1 / 2}\right)^{1 / 2} \Sigma_{z}^{-1 / 2}(n, n) \geq \Lambda(n, n) \geq$ $\frac{2}{2+\rho(K-1)} \Sigma_{z}^{-1 / 2}\left(\Sigma_{z}^{1 / 2} \Sigma_{\delta} \Sigma_{z}^{1 / 2}\right)^{1 / 2} \Sigma_{z}^{-1 / 2}(n, n)$. The definition of $\Lambda$ also implies that $\lim _{K \rightarrow \infty} \Lambda=O$ and that absolute market depth $\left(\frac{2}{\sqrt{K}}\left|\Lambda^{-1}\right|\right.$, where the absolute value of a matrix denotes the matrix of the absolute values of its elements) increases with the number of speculators $(K)$ and the intensity of noise trading $\left(\Sigma_{z}\right)$, because then the MMs perceive the threat of adverse selection as less serious. Similar results and intuition for the case of a single risky asset have been provided by Admati and Pfleiderer (1988) in a one-period framework, by Holden and Subrahmanyam (1992) and Foster and Viswanathan (1996) in a multi-period game, and by Back, Cao, and Willard (2000) in a continuous-time setting.
} 
equilibrium. According to Equation (11), $\operatorname{var}\left(P_{1}\right)$ is instead a permutation of $\Sigma_{\delta}$, the variance of the speculators' information advantage $\delta_{k}$ [Equation (4)]. We can think of $\Sigma_{\delta}$ as reflecting the true covariance structure of the economy $\left(\Sigma_{u}\right.$ and $\left.\beta \Sigma_{\vartheta} \beta^{\prime}\right)$, adjusted for the relative precision of the signals of $u$ and $\vartheta\left(\Sigma_{u} \Sigma_{S_{u}}^{-1}\right.$ and $\left.\Sigma_{\vartheta} \Sigma_{S_{\vartheta}}^{-1}\right)$. For example, if $\Sigma_{v}(3,1)=0$ in the threecountry economy of Equation (2), then $\Sigma_{\delta}(3,1)=0$ as well. In the presence of one or many homogeneously informed speculators, $H$ is diagonal $\left(\right.$ Remark 1) and $\operatorname{var}\left(P_{1}\right)=\frac{K}{2+\rho(K-1)} \Sigma_{\delta}$. Thus, in both cases, $\operatorname{var}\left(P_{1}\right)$ mimics the fundamental covariance structure $\Sigma_{v}$ embedded in $\Sigma_{\delta} .{ }^{20}$ For example, both $\Sigma_{v}(3,1)=0$ and $\operatorname{var}\left(P_{1}\right)(3,1)=0$ in Equation (2). In the presence of heterogeneously informed speculators, $H$ is nondiagonal (Remark 1) and $\operatorname{var}\left(P_{1}\right)$ departs from $\Sigma_{v}$. For example, if $K=15$, then $\operatorname{var}\left(P_{1}\right)$ $(3,1)=0.082$ although $\Sigma_{v}(3,1)=0$ in Equation (2). This discussion motivates our analysis of financial contagion next.

\section{International Financial Contagion}

The identification of empirical regularities in episodes of domestic and international financial turmoil is currently at the center of an intense debate in the literature. ${ }^{21}$ Nonetheless, a consensus has emerged that not only periods of uncertainty but also more tranquil times are generally accompanied by excess comovement among asset prices within and across both developed and emerging financial markets. Such comovement is often defined as comovement beyond the degree justified by economic fundamentals and financial contagion as the circumstance of its occurrence [e.g., Bekaert, Harvey, and Ng (2005)].

To investigate the channels through which shocks propagate across countries, I need to specify an alternative, albeit equivalent, definition of contagion that concentrates on the sources of these shocks. Consistent with Forbes and Rigobon (2002) and Kaminsky, Reinhart, and Vegh (2003), I say that financial contagion occurs when a shock to one market affects prices of other markets fundamentally unrelated either to that shock or to that market. I find this definition appealing because it allows to distinguish contagion from mere interdependence, the propagation of common external shocks (such as changes in oil prices or international interest rates) across countries due to real cross-market

\footnotetext{
${ }^{20}$ Nonetheless, $\operatorname{var}\left(P_{1}\right)$ is only a fraction of $\Sigma_{\delta}$ because the order flow is only partially revealing of the speculators' private information.

${ }^{21}$ An incomplete list includes Shiller (1989), King and Wadhwani (1990), Pindyck and Rotemberg (1990, 1993), King, Sentana, and Wadhwani (1994), Karolyi and Stulz (1996), Baig and Goldfajn (1999), Bekaert and Harvey (2000), Connolly and Wang (2000), Boyer, Kumagai, and Yuan (2002), Corsetti, Pericoli, and Sbracia (2002), Forbes and Rigobon (2002), Kallberg, Liu, and Pasquariello (2002, 2005), Kallberg and Pasquariello (2004), Barberis, Shleifer, and Wurgler (2005), Bekaert, Harvey, and Ng, (2005), and Pasquariello (2005).
} 
linkages. ${ }^{22}$ The following definition makes these concepts operational in my framework by means of comparative statics analysis.

Definition 2. In equilibrium, financial contagion from country $j$ to country $n$ occurs if, as a result of a real shock (to $u$ or $\vartheta$ ) or an information noise shock (to $\varepsilon_{u k}$ or $\varepsilon_{\vartheta k}$ ),

$$
\frac{\partial P_{1}(n)}{\partial S_{u k}(j)} \neq 0 \quad \text { or } \quad \frac{\partial P_{1}(n)}{\partial S_{\vartheta k}(f)} \neq 0, \quad \text { but } \beta(n, f)=0,
$$

or if, as a result of a noise trading shock (to z),

$$
\frac{\partial P_{1}(n)}{\partial z(j)} \neq 0
$$

Conversely, interdependence between country $n$ and country $j$ occurs if

$$
\frac{\partial P_{1}(n)}{\partial S_{\vartheta k}(f)} \neq 0, \quad \text { and } \beta(n, f) \neq 0 .
$$

The three-country example of Section 1.1 helps clarifying this definition. According to Equation (2), the terminal payoffs of the assets traded in countries 1 and $3(v(1)$ and $v(3))$ are fundamentally unrelated, that is, countries 1 and 3 do not share any common source of risk as follows:

$$
\begin{aligned}
& v(1)=u(1)+\vartheta(1) \\
& v(2)=u(2)+0.5 \vartheta(1)+0.5 \vartheta(2) \\
& v(3)=u(3)+\vartheta(2) .
\end{aligned}
$$

In such a setting, and according to Definition 2, financial contagion takes place when, for instance, a real idiosyncratic shock to country $1(d u(1)$, e.g., in Thailand) affects the equilibrium asset prices of country $3\left(d P_{1}(3)\right.$, e.g., in Brazil). ${ }^{23}$

\footnotetext{
${ }^{22}$ Several studies have explained the excessive interdependence among equilibrium asset prices, that is, the relatively high correlations in asset prices in the presence of relatively low correlations in fundamentals (e.g., the low extent of international intertemporal trade documented by Feldstein and Horioka, 1980), in the context of multiple-asset, multiple-good general equilibrium models without financial distortions. Examples of this literature are Helpman and Razin (1978), Cole and Obstfeld (1991), Zapatero (1995), Cochrane, Longstaff, and Santa-Clara (2003), Cass and Pavlova (2004), and Pavlova and Rigobon (2004). Similarly, two-country, single-good real business cycle models [e.g., Backus, Kehoe, and Kydland (1992), Baxter and Crucini (1993)] also generate greater cross-country correlation of consumption and productivity than cross-country correlation of output.

${ }^{23}$ Definition 2 also labels as financial contagion the circumstances in which an idiosyncratic shock to one country affects the equilibrium asset prices of a fundamentally related country. This would be the case if,
} 


\subsection{Real shocks and contagion}

Real idiosyncratic $(d u(n))$ and systematic $(d \vartheta(f))$ shocks are shocks to the terminal payoffs of a country's assets $(v(n))$. In the previous section, I described a model of multi-asset trading in which all traditional channels through which these shocks may induce contagion among financial markets (correlated information, correlated liquidity, and portfolio rebalancing) have been ruled out by construction. In this section, I propose a novel explanation of financial contagion that uses two realistic market frictions, imperfect competition among speculators and heterogeneity of their information, in the context of our stylized economy. I first introduce the intuition for this novel propagation mechanism in the context of the simple three-country economy of Equation (2). I then show that this intuition is robust to the general case of Equation (1).

For instance, ceteris paribus, assume that a negative idiosyncratic shock to country 1 takes place: $d u(1)<0$. This shock is going to affect negatively the value of country 1's assets in the long-run (at $t=2$ ). In the short-run (at $t=1)$, the shock reflects into each of the $K$ signals $S_{u k}(1)$ and prompts all speculators to decrease their optimal demands for that security. The MMs observe the resulting outflow from country 1 $\left(d \omega_{1}(1)<0\right)$ and revise downward their beliefs about $v(1)$, therefore the equilibrium price $P_{1}(1) .{ }^{24}$ To prevent this $d P_{1}(1)<0$ from eroding their expected profits from the trade in country 1 , the speculators also buy more (sell fewer) units of country 2's index. ${ }^{25}$ This trade leads in fact the MMs to the incorrect inference not only that good news for country 2 may have occurred as well but also that such news may be due to a positive systematic shock $d \vartheta(1)>0$, because country 2 is exposed to this factor $(\beta(2,1)>0)$. The ensuing revision in $\mathrm{MMs}$ ' beliefs (higher $\left.E\left[\vartheta(1) \mid \omega_{1}\right]\right)$ attenuates the drop in $P_{1}(1)$, because country 1 too is exposed to $\vartheta(1)(\beta(1,1)>0)$, yet it comes at the cost of an increase in the price of country 2 's assets $\left(d P_{1}(2)>0\right)$, so of greater expected losses for the speculators from their trades in index $2\left(d X_{k}(2)>0\right)$. Moreover, the exposure of country 2 to $\vartheta(2)(\beta(2,2)>0)$ ends up mitigating the impact of those trades on the dealers' beliefs about $\vartheta(1)$. Thus, using the fact that $\beta(3,2)>0$, the speculators sell more (buy fewer) units of country 3's index to induce the MMs to adjust their beliefs about $\vartheta(2)$

\footnotetext{
for instance, a real idiosyncratic shock to country $1(d u(1)$, e.g., in Thailand) affects the equilibrium asset prices of country $2\left(d P_{1}(2)\right.$, e.g., in Germany), because countries 1 and 2 share a common exposure to the systematic factor $\vartheta(1)$. In what follows, to address the crux of financial contagion, we concentrate on the more challenging problem of explaining the propagation of shocks across fundamentally unrelated markets [e.g., countries 1 and 3 in Equation (2)].

${ }^{24}$ Indeed, $\Lambda(1,1)>0$ because the matrix $\Lambda$ is SPD.

${ }^{25}$ For example, $\frac{\partial X_{k}(2)}{\partial u(1)}=C \Sigma_{u} \Sigma_{S_{u}}^{-1}(2,1)=-0.061$ if $K=15$ and $H$ is nondiagonal.
} 
downward and about $\vartheta(1)$ upward, hence to mitigate both $d P_{1}(2)>0$ and $d P_{1}(1)<0 .{ }^{26}$

In short, the MMs know the structure of the economy of Equation (2). Hence, they rationally use the order flow for each country's assets to crossinfer new information about the payoffs of other countries' assets. Imperfectly competitive speculators, aware of this learning process, do not trade on each asset independently but choose each trade strategically to minimize the information divulged by their market orders. ${ }^{27}$ In the example above, the speculators, albeit risk-neutral and financially unconstrained, trade across countries (not only $d X_{k}(1)<0$ but also $d X_{k}(2)>0$ and $d X_{k}(3)<0$ ) to dissipate as little as possible of their initial informational advantage about the idiosyncratic shock to country 1 . The MMs account for the speculators' expected strategic trading when updating their priors on asset values from the observed aggregate order flow. Their ability to do so partially or in full determines whether excess comovement arises in the economy.

Eventually, the perceived possibility that $d \vartheta(1)>0$ and $d \vartheta(2)<0$ leads the MMs to set a smaller $d P_{1}(1)<0$, thus allowing greater profits for the speculators than if they had traded exclusively in index 1 . I am, however, interested in the circumstances under which the equilibrium prices in countries 2 and 3 do change as well in response to the speculators' trading activity. For that purpose, I recur to the analysis of speculators' trading behavior in Section 1.4. When there is only one or many homogeneously informed speculators, their strategic trading activity is correctly anticipated by the MMs, resulting in no financial contagion in response to the negative idiosyncratic shock to country 1: $d P_{1}(2)=0$ and $d P_{1}(3)=0$. Intuitively, the presence of only one speculator limits MMs' uncertainty surrounding his strategy in the order flow $\left(\omega_{1}\right)$. A larger number of homogeneously informed speculators does not increase this uncertainty. In fact, their trades are either identical or expected to be perfectly correlated, because so is their informational advantage $\left(\delta_{k}=\delta_{i}\right.$ or $\left.E_{1}^{k}\left(\delta_{i}\right)=\rho \delta_{k}\right)$. Their resulting quasi-competitive behavior makes $\omega_{1}$ a sufficient statistic for the MMs to avoid incorrect crossinference about $v$ in $P_{1}$. Heterogeneous information instead induces the speculators to quasi-monopolistic trading, because part of each's informational advantage is known exclusively to him. Indeed, their market orders are expected to be less than perfectly correlated (because $E_{1}^{k}\left(\delta_{i}\right) \neq \rho \delta_{k}$ ). Consequently, in equilibrium, the MMs learn less accurately about any private signal and any individual trading activity. ${ }^{28}$ The ensuing incorrect

\footnotetext{
${ }^{26} \overline{\text { For example, }}, \frac{\partial X_{k}(3)}{\partial u(1)}=C \Sigma_{u} \Sigma_{S_{u}}^{-1}(3,1)=0.027$ if $K=15$ and $H$ is nondiagonal.

${ }^{27}$ Both the matrices $\Lambda$ in Equation (9) for $P_{1}$ and $C$ in Equation (10) for $X_{k}$ are in fact nondiagonal in equilibrium.

${ }^{28}$ Consistently with this interpretation, Grinblatt and Ross (1985) showed that the impact of the actions of an insider behaving like a Stackelberg leader on the noisy rational expectations equilibrium of a twoperiod economy with one risky security and other perfectly competitive traders is significant only when all agents have less than perfectly correlated private information.
} 
cross-inference about fundamentals causes financial contagion among countries' asset prices: $d P_{1}(2)>0$ and $d P_{1}(3)<0$ in response to $d u(1)<0 .^{29}$

The cross-inference activity of the MMs plays a crucial role in the above intuition. If MMs were not attempting to learn the payoff of one asset from the order flow in other assets, then speculators would have no incentive to trade on their informational advantage strategically. Cross-inference can take place only if the underlying economy is fundamentally interconnected, that is, only if $\beta \neq O$ in Equation (1). This is the case in the stylized economy of Equation (2). If the underlying economy is instead fundamentally autarkic, that is, if $\beta=O$ in Equation (1), neither cross-inference, strategic portfolio rebalancing, nor contagion takes place in equilibrium. For instance, if $v(1)=u(1), v(2)=u(2)$, and $v(3)=u(3)$ in Equation (2), then $d P_{1}(2)=d P_{1}(3)=0$ in response to $d u(1)<0$, regardless of whether the speculators are homogeneously or heterogeneously informed.

In Figure 1, I plot the impact of a real idiosyncratic shock to the terminal value of index 1 on the equilibrium price of index 3 as a function of the number of speculators in the economy $(K)$ and for different degrees of their information heterogeneity. Specifically, I calibrate the information

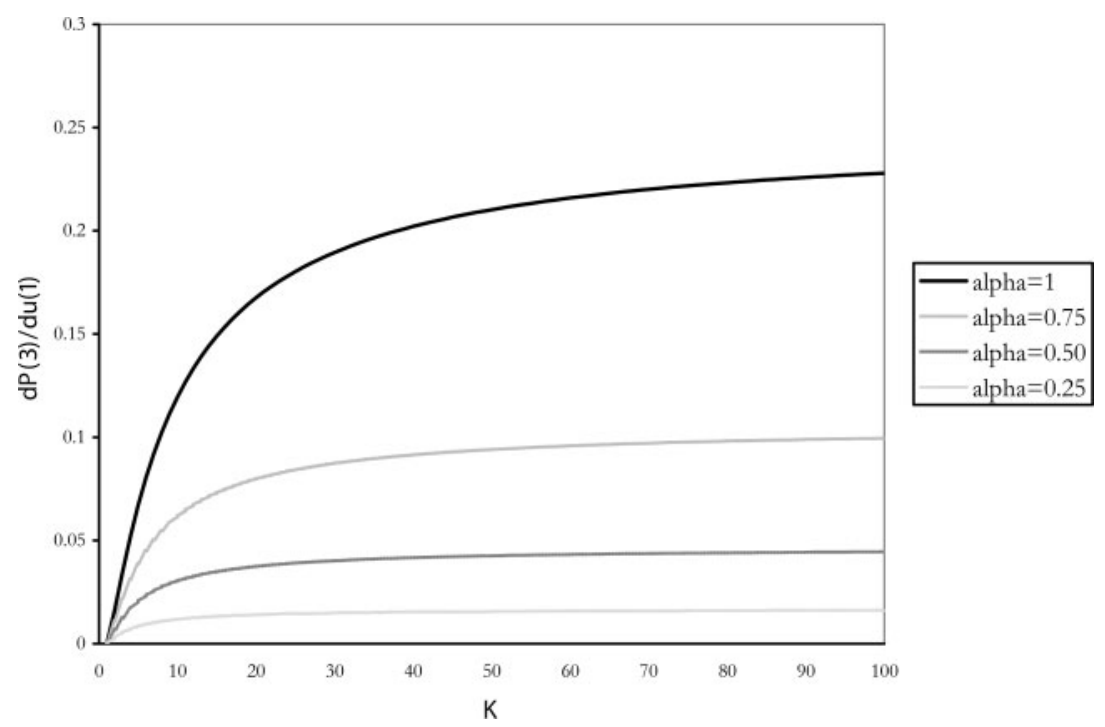

Figure 1

Three-country economy: contagion from real shocks

Figure 1 plots a measure of contagion from real shocks in the three-country economy of Equation (2), $\left[\frac{\partial P_{1}(3)}{\partial u(1)}\right]$ of Proposition 2, as a function of the number of better informed speculators $(K)$, given its parametrization in Appendix B. I compute $\left[\frac{\partial P_{1}(3)}{\partial u(1)}\right]$ for different values of $\alpha$ in $\Sigma_{c}^{*}=\alpha \Sigma_{c}+(1-\alpha) \rho \Sigma_{\delta}$, that is, for different degrees of information heterogeneity.

${ }^{29} \overline{\text { E.g., } d P_{1}(2)}=0.055$ and $d P_{1}(3)=-0.149$ if $d u(1)=-1$ and $K=15$. 
settiing of Section 1.2 as follows: I define $\Sigma_{c}^{*}=\alpha \Sigma_{c}+(1-\alpha) \rho \Sigma_{\delta}$, assume that $\operatorname{cov}\left(\delta_{k}, \delta_{i}\right)=\Sigma_{c}^{*}$, and finally substitute $\Sigma_{c}$ with $\Sigma_{c}^{*}$ in Proposition 1 . We can then interpret the parameter $\alpha \in[0,1]$ as a proxy for the extent of dispersion of speculators' information, from the lowest (information homogeneity: $\alpha=0$ and $\Sigma_{c}^{*}=\rho \Sigma_{\delta}$ ) to the highest (maximal information heterogeneity: $\alpha=1$ and $\Sigma_{c}^{*}=\Sigma_{c} \neq \rho \Sigma_{\delta}$ ). Figure 1 shows that the contagion measure $\left[\frac{\partial P_{1}(3)}{\partial u(1)}\right]$ is positive, even though countries 1 and 3 are ex ante unrelated $\{\operatorname{cov}[v(1), v(3]=0\}$, only when $\alpha>0$. There is no financial contagion $\left\{\left[\frac{\partial P_{1}(3)}{\partial u(1)}\right]=0\right\}$ when speculators are homogeneously informed $(\alpha=0)$.

Accordingly, although countries 1 and 3 are ex ante uncorrelated, that is, $\operatorname{corr}[v(1), v(3)]=0$ in Equation (2), the unconditional correlation between those countries' equilibrium prices is positive in the presence of heterogeneously informed speculators \{e.g., $\operatorname{corr}\left[P_{1}(1), P_{1}(3)\right]=0.036$ if $K=15$ \} but zero in the presence of homogeneously informed speculators. Unconditional correlation is nonetheless a less adequate measure of the intensity of financial contagion than the conditional comparative statics in Definition 2 . The former is in fact computed over all possible realizations of independent (thus offsetting) sources of risk in the model $\left(u, \vartheta, \varepsilon_{u}, \varepsilon_{\vartheta}\right.$, and $z$ ), whereas the latter is computed in response to shocks to either of those risks, ceteris paribus for the others. For instance, in the example above, conditional on idiosyncratic shocks to country 1 and ceteris paribus for any other shock, the ensuing changes in the equilibrium asset prices of countries 1 and 3 are perfectly correlated when speculators' information is heterogeneous and uncorrelated otherwise. Indeed, evidence of both high asset price correlations and low correlation of fundamentals is often found only during short periods of financial turmoil following large domestic shocks rather than over extended sample periods [e.g., Kaminsky, Reinhart, and Vegh (2003), Bekaert, Harvey, and Ng (2005)]. ${ }^{30}$

The extent of financial contagion from country 1 to country 3 is increasing in $K$ and $\alpha$. A greater number of heterogeneously informed speculators (higher $K$ ) makes it more difficult for the MMs to learn their individual trades. More asymmetric sharing of private information among speculators (higher $\alpha$ ) induces a greater impact of $d u(1)$ on $P_{1}(3)$, because it makes MMs' cross-inference more incorrect. For instance, it can be shown that in the economy of Equation (2), when $\alpha=1$, the resulting excess comovement explains up to $21 \%$ of the unconditional variance of $P_{1}(3)$ due to private information about $v$.

\footnotetext{
${ }^{30}$ Furthermore, it can be shown that in my model, when speculators are heterogeneously informed, equilibrium excess comovement leads to greater unconditional price volatility as well. This effect may in turn attenuate the increase in equilibrium unconditional price correlation among fundamentally uncorrelated assets but not the conditional contagion measures in Definition 2.
} 
2.1.1 A general result. The propagation mechanism described above is not specific to the three-country setting of Equation (2). The following proposition generalizes the intuition of financial contagion from real shocks to the economy of Equation (1).

Proposition 2. The impact of shocks to $u$ on $P_{1}$ is given by the $N \times N$ matrix

$$
\frac{\partial P_{1}}{\partial u^{\prime}}=K H \Sigma_{u} \Sigma_{S_{u}}^{-1},
$$

whereas the impact of shocks to $\vartheta$ on $P_{1}$ is given by the $N \times F$ matrix

$$
\frac{\partial P_{1}}{\partial \vartheta^{\prime}}=K H \beta \Sigma_{\vartheta} \Sigma_{S_{\vartheta}}^{-1} .
$$

When $\beta \neq O$, there is financial contagion from those shocks if and only if speculators are heterogeneously informed. Then, both $\left|\frac{\partial P_{1}(n)}{\partial u(j)}\right| \neq 0$ and $\left|\frac{\partial P_{1}(n)}{\partial \vartheta(f)}\right| \neq 0$ are increasing in $K$ and $\alpha$ but independent from the intensity of noise trading. ${ }^{31}$ When $\beta=O$, there is no such contagion.

According to Definition 2, the off-diagonal terms in Equations (15) and (16) measure the magnitude of contagion by real shocks. The assumptions in Section 2 (all covariance matrices $\Sigma_{u}, \Sigma_{\vartheta}, \Sigma_{\varepsilon_{u}}, \Sigma_{\varepsilon_{\vartheta}}$, and $\Sigma_{z}$ being diagonal and risk-neutrality) deactivate the channels of financial contagion already explored by the literature (correlated information, correlated liquidity, and portfolio rebalancing) by construction. In this setting, Proposition 2 states that when the economy is fundamentally autarkic $[\beta=O$ in Equation (1)], that is, when all its fundamentals are unrelated, so are its equilibrium asset prices. Hence, financial contagion does not arise in my model \{i.e., $\left.\left[\frac{\partial P_{1}(n)}{\partial u(j)}\right]=0\right\}$. When the economy is instead fundamentally interconnected $[\beta \neq O$ in Equation (1)], the impact of real shocks on equilibrium prices depends on the matrix $H$ defined in Proposition 1, the number of speculators $(K)$, and their signals' relative precision $\left(\Sigma_{u} \Sigma_{S_{u}}^{-1}\right.$ for $S_{u k}$ and $\Sigma_{\vartheta} \Sigma_{S_{\vartheta}}^{-1}$ for $\left.S_{\vartheta k}\right)$. When speculators are homogeneously informed, the matrix $H$ is diagonal (Remark 1$): H=\left[\frac{1}{2+\rho(K-1)}\right] I$. Hence, any adjustment in the equilibrium price vector due to real shocks mirrors the fundamental

\footnotetext{
${ }^{31}$ Because $H$ is not symmetric, upper and lower triangular terms in $\frac{\partial P_{1}}{\partial u}$ and $\frac{\partial P_{1}}{\partial \vartheta}$ may be different from each other. Additionally, it can be shown that $\lim _{K \rightarrow \infty} \frac{\partial P_{1}}{\partial u}=\Sigma_{\delta}\left(\Sigma_{c}^{*}\right)^{-1} \Sigma_{u} \Sigma_{S_{u}}^{-1}$ and $\lim _{K \rightarrow \infty} \frac{\partial P_{1}}{\partial \vartheta}=\Sigma_{\delta}\left(\Sigma_{c}^{*}\right)^{-1} \beta \Sigma_{\vartheta} \Sigma_{S_{\vartheta}}^{-1} \quad$ when $\Sigma_{c}^{*}=\alpha \Sigma_{c}+(1-\alpha) \rho \Sigma_{\delta} \quad$ but $H \neq\left[\frac{1}{2+\rho(K-1)}\right] I$. When instead $H=\left[\frac{1}{2+\rho(K-1)}\right] I$, it ensues that $\lim _{K \rightarrow \infty} \frac{\partial P_{1}}{\partial u}=\frac{1}{\rho} \Sigma_{u} \Sigma_{S_{u}}^{-1}$ and $\lim _{K \rightarrow \infty} \frac{\partial P_{1}}{\partial \vartheta}=\frac{1}{\rho} \beta \Sigma_{\vartheta} \Sigma_{S_{\vartheta}}^{-1}$.
} 
economy of Equation (1). Only when speculators' information about these shocks is heterogeneous, the matrix $H$ is nondiagonal (Remark 1) and financial contagion does arise in my model $\left\{\right.$ e.g., $\left.\left[\frac{\partial P_{1}(n)}{\partial u(j)} \neq 0\right]\right\}$, the more so the greater are $K$ and $\alpha$.

These implications find empirical support in recent studies of contagion within and across financial markets. For example, Kallberg and Pasquariello (2004) found that excess comovement in the US stock market over the last three decades is positively related to the dispersion of analysts' earning forecasts, a proxy for information heterogeneity suggested by Diether, Malloy, and Scherbina (2002). Furthermore, many empirical studies of institutional and foreign investors' trading behavior offer supporting evidence of intense portfolio rebalancing, rather than generalized sales of assets, during recent financial crises in developing economies [e.g., Borensztein and Gelos (2000), Kaminsky, Lyons, and Schmukler (2000, 2001), Kallberg, Liu, and Pasquariello (2005)]. Accordingly, Disyatat and Gelos (2001) showed that those investors' holdings contain reliable information about future returns in emerging markets.

The price effects in Equations (15) and (16) should be interpreted as financial contagion over a relatively short period of time $(t=1)$, that is, short enough for the fundamentals and factor loadings in Equation (1) to be taken as given, thus short enough for meaningful comparative statics analysis. This is not too restrictive, because it is consistent with extant empirical evidence suggesting that, in proximity of most financial crises, conjoined asset price changes are often not only sudden and excessive but also short-lived [e.g., Forbes and Rigobon (2002), Kaminsky, Reinhart, and Vegh (2003), Bekaert, Harvey, and Ng (2005)]. Furthermore, in the long-run $(t=2)$, the announced liquidation values constitute the terminal prices of the $N$ assets: $P_{2}(n)=v(n)$. Hence, a portion of the price adjustments between $t=1$ and $t=2$ can also be deemed excessive, because it is meant to reverse the previously excessive price changes that took place between $t=0$ and $t=1 .{ }^{32}$

The intensity of financial contagion from real shocks does not depend on the amount of liquidity trading (i.e., on $\Sigma_{z}$ ), because more noise in the

\footnotetext{
${ }^{32}$ Take, for instance, the economy of Equation (2) in the presence of information heterogeneity $(\alpha>0)$. In such a setting (e.g., Figure 1), Proposition 2 argues that, in response to a negative idiosyncratic shock to country $1(d u(1)<0)$, both $d P_{1}(1)<0$ (partial convergence to payoff) and $d P_{1}(3)<0$ (contagion) occur in the first period (short-term). Liquidation at $t=2$ then implies that both $d P_{2}(1)<0$ (final convergence to payoff) and $d P_{2}(3)=-d P_{1}(3)>0$ (reversal to payoff) occur in the second period (long-term). The latter reversal is necessary, because $v(3)$ is unaffected by $d u(1)<0$. Therefore, both $\operatorname{cov}\left[d P_{1}(1), d P_{1}(3)\right]>0$ and $\operatorname{cov}\left[d P_{2}(1), d P_{2}(3)\right]<0$ are excessive, given that $\operatorname{cov}[v(1), v(3)]=0$. Nonetheless, $\operatorname{cov}\left[d P_{1}(1), d P_{1}(3)\right]+\operatorname{cov}\left[d P_{2}(1), d P_{2}(3)\right]=0$ by construction, for it is equivalent to $\operatorname{cov}[v(1), v(3)]$. Indeed, if we define the vectors $\Delta P_{1}=P_{1}-P_{0}$ and $\Delta P_{2}=P_{2}-P_{1}=v-P_{1}$, it can be shown that $\operatorname{var}\left(\Delta P_{1}\right)+\operatorname{var}\left(\Delta P_{2}\right)=\operatorname{var}(v)=\Sigma_{v}$. This example also suggests that long-term price reversal may lead traditional empirical measures of comovement (e.g., the correlation of time series of price changes) to underestimate the extent of financial contagion. For more on alternative measures of excess comovement, see Corsetti, Pericoli, and Sbracia (2002) and Kallberg and Pasquariello (2004).
} 
order flow leaves its information content (and the MMs' cross-inference) unchanged in equilibrium. This result suggests that noise trading, often accused to exacerbate the propagation of shocks across assets or markets, does not play any role in explaining excess comovement in my model. Noise trading is nonetheless what prevents the aggregate order flow from becoming a sufficient statistic for $S_{u k}$ and $S_{\vartheta k}$ in the first place. Hence, $\Sigma_{z}$ controls for the degree of information asymmetry in this economy. Then, Proposition 2 implies that changes in the intensity of information asymmetry per se do not affect the vulnerability of a market to financial contagion unless those changes are accompanied by information heterogeneity among speculators.

2.1.2 Vulnerability to contagion. Financial turmoil often propagates across fundamentally unrelated emerging economies. In those countries, financial contagion has enormous economic and social costs. Understanding its causes and devising ways to prevent its occurrence are therefore topics of pressing interest to economists and policymakers. My model may help explain why some emerging markets are especially vulnerable (and increasingly so) to episodes of financial contagion.

For that purpose, I return to the three-country economy of Equation (2), in which assets 1 and 3 can be interpreted as the market indexes of developing countries (e.g., Thailand and Brazil, respectively) and country 2 can be thought of as a developed economy (e.g., Germany). Within this setting, assume for instance that only for country 1 and only for $u(1)$ do speculators share private information asymmetrically: $S_{u k}(1) \neq S_{u i}(1)$ but $S_{u k}(n)=S_{u i}(n)$ and $S_{\vartheta k}(f)=S_{\vartheta i}(f)$ for $n=\{2,3\}$ and $f=\{1,2\}$. This assumption translates into information heterogeneity among sophisticated market participants exclusively about future realizations of local macroeconomic factors in Thailand. ${ }^{33}$

In the resulting equilibrium, shocks from country 1 do not affect countries 2 and 3 , but shocks to $u(3)$ and $\vartheta(2)$ do affect the equilibrium price $P_{1}(1)$, although both $u(3)$ and $\vartheta(2)$ are uncorrelated to $v(1) .^{34}$ Equivalently, only Thailand is vulnerable to shocks originating in Brazil and/or Germany, yet idiosyncratic shocks to Thailand do not propagate to Brazil and Germany. Intuitively, this occurs because the MMs learn from the aggregate order flow about the speculators' strategic trading in the assets of countries 2 (Germany) and 3 (Brazil) with sufficient precision to avoid incorrect cross-inference about their liquidation values but not

\footnotetext{
${ }^{33}$ Equations (4) and (5) in fact imply that $\Sigma_{c}=\Sigma_{\delta}$ with the exception of $\Sigma_{c}(1,1)=$ $\Sigma_{u} \Sigma_{S_{u}}^{-1} \Sigma_{u} \Sigma_{S_{u}}^{-1} \Sigma_{u}(1,1)+\beta \Sigma_{\vartheta} \Sigma_{S_{v}}^{-1} \Sigma_{\vartheta} \beta^{\prime}(1,1)=2.880, \quad$ whereas $\Sigma_{\delta}(1,1)=\Sigma_{u} \Sigma_{S_{u}}^{-1} \Sigma_{u}(1,1)+\beta \Sigma_{\vartheta} \Sigma_{S_{v}}^{-1} \Sigma_{\vartheta} \beta^{\prime}$ $(1,1)=3.103$.

${ }^{34}$ For example, if $K=15$ and $\alpha=1$, then the effect of $d u(3)=-1$ on $P_{1}(1)$ is given by $d P_{1}(1)=-0.085$, yet $d P_{1}(2)=d P_{1}(3)=0$ in response to any $d u(1) \neq 0$.
} 
enough to prevent incorrect cross-inference about country 1 (Thailand). Contagion then ensues.

Thus, heterogeneity of private information about domestic sources of risk in a country makes that country more vulnerable to fundamentally unrelated shocks from other countries, that is, increases the likelihood and magnitude of financial contagion. Consistently, significant and persistent differences in private information among traders are more likely to be observed in less mature, less heavily supervised financial markets, like the ones of less developed economies where the process of generation and acquisition of information is still not sufficiently standardized. Homogeneous private information about developed economies can only attenuate but not eliminate excess comovement among developing markets. ${ }^{35}$ Proposition 2 therefore suggests that policymakers and international organizations may be able to reduce these markets' vulnerability to contagion reducing the degree of asymmetric sharing of private information about them among sophisticated investors. This could be accomplished, for example, by encouraging the adoption of uniform and stringent regulations across emerging financial markets for the generation and disclosure of corporate and macroeconomic information.

The degree of uncertainty surrounding countries' long-run asset values $(v)$ also affects the accuracy of the MMs' updating process, hence equilibrium excess comovement. Assume for instance that, in the economy of Equation (2), $\Sigma_{u}(3,3)=\mu$, such that the scalar $\mu$ controls for the variance of local macroeconomic risks in country $3(u(3))$. In Figure 2, we plot $\left[\frac{\partial P_{1}(3)}{\partial u(1)}\right]$ as a function of $\mu$ when speculators are heterogeneously informed $(\alpha=1)$. Consistent with empirical evidence in Connolly and Wang (2000), greater idiosyncratic volatility for a country's economy initially makes that country's excess price comovement more severe $\left\{\left[\frac{\partial P_{1}(3)}{\partial u(1)}\right]\right.$ is higher $\}$. Intuitively, the greater is $\mu$, the greater is the perceived quality of speculators' signals of $u(3)\left(\Sigma_{u} \Sigma_{S_{u}}^{-1}(3,3)\right.$ is higher), hence the more uninformed dealers rely upon the observed order flow to learn about $v(3)$. Indeed, casual empiricism suggests that a sudden increase in a developing country's local macroeconomic uncertainty (e.g., due to domestic political events such as the strikes and protests sweeping Indonesia and the transition of power following presidential elections in South Korea in 1997) may suddenly raise that country's vulnerability to external shocks (e.g., the devaluation of the Thai baht in July 1997 or the LTCM collapse in September 1998). However, when the order flow becomes a more reliable source of information, incorrect cross-inference by the MMs becomes less significant as well. The latter

\footnotetext{
${ }^{35}$ For example, if $S_{u k}(2)=S_{u}(2), K=15$, and $\alpha=1$, then in equilibrium $d P_{1}(2)=0.003$ and $d P_{1}(3)=-0.113$ in response to $d u(1)=-1$.
} 


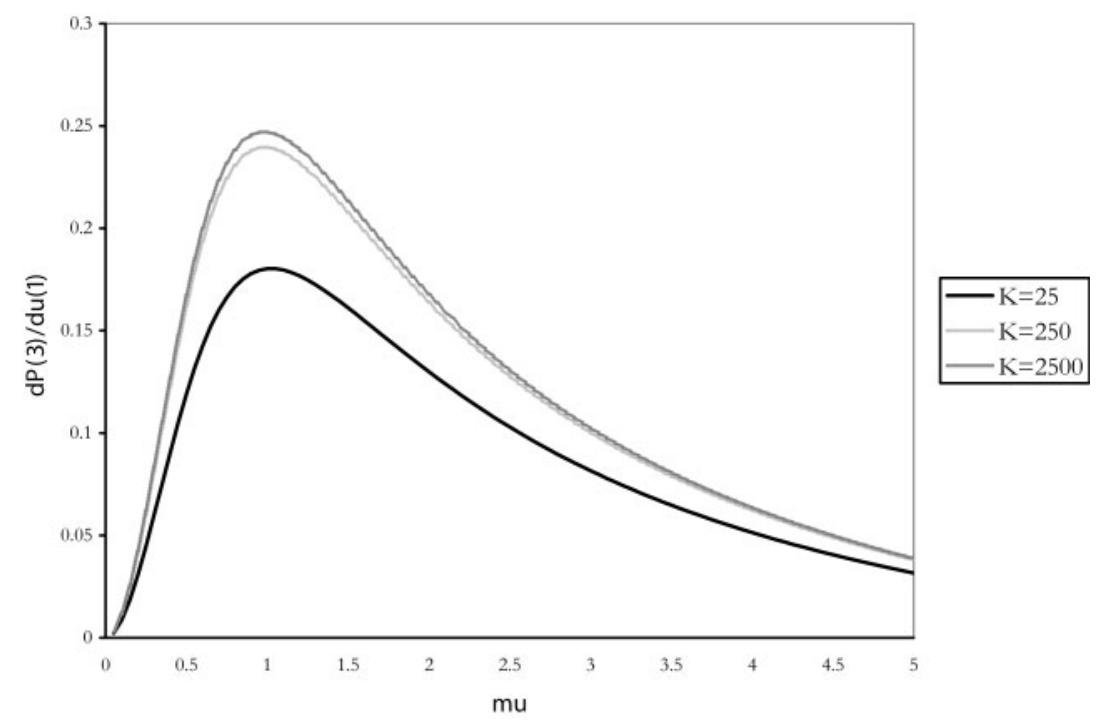

Figure 2

Three-country economy: contagion from real shocks

Figure 2 plots a measure of contagion from real shocks in the three-country economy of Equation (2), $\left[\frac{\partial P_{1}(3)}{\partial u(1)}\right]$ of Proposition 2, as a function of $\mu(\mathrm{mu})$, a proxy for the uncertainty surrounding $u(3)$ when $\Sigma_{u}$ is equal to the matrix reported in Equation (B1) except $\Sigma_{u}(3,3)=\mu$. I compute $\left[\frac{\partial P_{1}(3)}{\partial u(1)}\right]$ for different numbers of better informed speculators $(K)$ when $\alpha=1$ in $\Sigma_{c}^{*}=\alpha \Sigma_{c}+(1-\alpha) \rho \Sigma_{\delta}$, that is, when their information is heterogeneous.

effect eventually prevails for higher values of $\mu$, and the magnitude of contagion from country 1 to country 3 declines. Yet again, if speculators are homogeneously informed $(\alpha=0)$, then there is no financial contagion in Equation (2) $\left\{\right.$ e.g., $\left.\left[\frac{\partial P_{1}(3)}{\partial u(1)}\right]=0\right\}$ regardless of countries' macroeconomic uncertainty.

In their study of multi-asset hedging due to risk aversion, Kodres and Pritsker (2002) attributed the recurrence of episodes of financial contagion in emerging markets to their greater degree of information asymmetry. It is arguably the case that reliable information is generally accessible to fewer players in those economies. Nonetheless, the increased interest of professional money managers in them, spurred by the process of financial integration and liberalization of the past two decades [e.g., Bekaert, Harvey, and Lumsdaine (2002)], should have led to lower (and not higher) information asymmetry, so decreasing (and not increasing) their vulnerability to contagion. Proposition 2 and the above examples instead imply that information asymmetry is only a necessary, but not a sufficient, condition for excess comovement among the equilibrium prices of fundamentally unrelated markets. Proposition 2 also suggests that such integration process may 
have instead raised the intensity of contagion episodes, because a greater number of sophisticated market participants makes it more difficult for the MMs to learn their individual trades (Figure 1).

\subsection{Information noise shocks and contagion}

In my model, speculators receive noisy signals of the idiosyncratic and systematic risks in the economy ( $S_{u k}$ and $S_{\vartheta k}$ ). Shocks to the errors in these signals $\left(\varepsilon_{u k}\right.$ and $\left.\varepsilon_{\vartheta k}\right)$ may also induce contagion, as shown in the following proposition.

Proposition 3. The impact of shocks to any $\varepsilon_{u k}$ on $P_{1}$ is given by the $N \times N$ matrix

$$
\frac{\partial P_{1}}{\partial \varepsilon_{u k}^{\prime}}=H \Sigma_{u} \Sigma_{S_{u}}^{-1},
$$

whereas the impact of shocks to any $\varepsilon_{\vartheta k}$ on $P_{1}$ is given by the $N \times F$ matrix

$$
\frac{\partial P_{1}}{\partial \varepsilon_{\vartheta k}^{\prime}}=H \beta \Sigma_{\vartheta} \Sigma_{S_{\vartheta}}^{-1}
$$

When $\beta \neq O$, there is financial contagion from those shocks if and only if speculators are heterogeneously informed. Then, both $\left|\frac{\partial P_{1}(n)}{\partial \varepsilon_{u k}(j)}\right| \neq 0$ and $\left|\frac{\partial P_{1}(n)}{\partial \varepsilon_{v k}(f)}\right| \neq 0$ are independent from the intensity of noise trading. When $\beta=O$, there is no such contagion.

When the economy is fundamentally interconnected $[\beta \neq O$ in Equation (1)], a shock to $S_{u k}$ or $S_{\vartheta k}$ has the same effect on a speculator's informational advantage $\delta_{k}$ whether it is induced by real shocks (to $u$ and $\vartheta$ ) or by information noise shocks (to $\varepsilon_{u k}$ and $\varepsilon_{\vartheta k}$ ). However, any $d u$ or $d \vartheta$ modifies the signals observed by all speculators, hence has a bigger impact on $P_{1}$. Shocks to $\varepsilon_{u k}$ or $\varepsilon_{\vartheta k}$ lead only speculator $k$ to the incorrect inference that a fundamental event took place and induce him alone to revise his portfolio strategically. Information asymmetry prevents the MMs from learning whether the resulting $d \omega_{1}$ is due to news or noise. Information heterogeneity prevents the MMs from learning whether that shock is due to idiosyncratic or systematic news. Incorrect cross-inference by the MMs and contagion may then occur, as in the stylized economy of Equation (2) $\left\{\right.$ e.g., $\left[\frac{\partial P_{1}(3)}{\partial \overline{\tau u k}(1)}\right]>0$ in Figure 3$\}$. Thus, Proposition 3 suggests that financially unrelated markets in which private information is shared asymmetrically may experience excess price comovements as a result not only of real shocks but also of false and misleading information about the fundamentals of a single country in the hands of one or few speculators. 


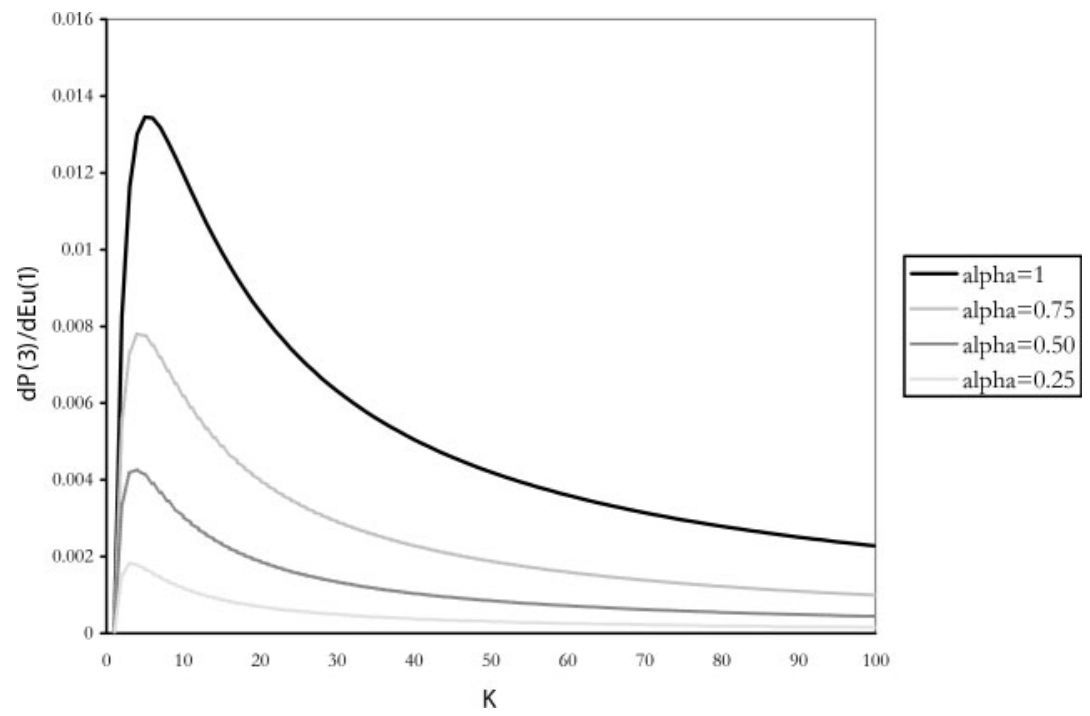

Figure 3

Three-country economy: contagion from information noise shocks

Figure 3 plots a measure of contagion from individual information noise shocks in the three-country economy of Equation (2), $\left[\frac{\partial P_{1}(3)}{\partial \varepsilon_{u k}(1)}\right]$ of Proposition 3, as a function of the number of better informed speculators $(K)$, given its parametrization in Appendix B. I compute $\left[\frac{\partial P_{1}(3)}{\partial \varepsilon_{u k}(1)}\right]$ for different values of $\alpha$ in $\Sigma_{c}^{*}=\alpha \Sigma_{c}+(1-\alpha) \rho \Sigma_{\delta}$, that is, for different degrees of information heterogeneity.

As in Proposition 2, both $\left|\frac{\partial P_{1}(n)}{\partial \varepsilon_{u k}(j)}\right|$ and $\left|\frac{\partial P_{1}(n)}{\partial \varepsilon_{\vartheta k}(f)}\right|$ are unambiguously unrelated to the intensity of noise trading, so is the information content of the order flow. The impact of the number of informed traders $(K)$ on their magnitude is instead the result of two contrasting effects. An increasing number of heterogeneously informed speculators makes it more difficult for the MMs to learn about their less than perfectly correlated trading strategies. However, a bigger $K$ also makes the order flow $\left(\omega_{1}\right)$ more informative about fundamentals and the equilibrium prices $\left(P_{1}\right)$ less sensitive to individual trades (i.e., $|\Lambda|$ smaller). For a small $K$, the former might dominate the latter, so inducing greater contagion (as in Figure 3). Yet, for a big $K$, as competition among speculators and the information content of $\omega_{1}$ increases, the incorrect cross-inference from a shock to $\varepsilon_{u k}$ or $\varepsilon_{\vartheta k}$ eventually has a negligible effect on $P_{1} \cdot{ }^{36}$ Hence, according to our model, rising participation of sophisticated investors to multi-market trading (e.g., due to the integration of world capital markets) may reduce the vulnerability of all countries to contagion from information noise although it increases the magnitude of contagion from real shocks (Proposition 2).

\footnotetext{
${ }^{36} \overline{\text { Accordingly }}, \lim _{K \rightarrow \infty} H=O$ regardless of $\alpha$.
} 


\subsection{Noise-trading shocks and contagion}

Liquidity (or noise) trading plays an important role in our model. Its presence makes the order flow only partially revealing about $v$, hence MMs' incorrect cross-inference from shocks to speculators' signals possible in equilibrium. Noise trading also provides a more direct channel for financial contagion, as the following proposition illustrates.

Proposition 4. The impact of shocks to $z$ on $P_{1}$ is given by the $N \times N$ matrix

$$
\frac{\partial P_{1}}{\partial z^{\prime}}=\frac{\sqrt{K}}{2} \Lambda
$$

When $\beta \neq O$, the existence of contagion from those shocks $\left(\left|\frac{\partial P_{1}(n)}{\partial z(j)}\right| \neq 0\right)$ does not depend on the number of speculators $(K)$ or on whether they share information asymmetrically $(H)$. When $\beta=O$, there is no such contagion.

In our model, realizations of $z$ are unobservable and can be interpreted as caused by supply shocks, shifts to life-cycle motivations, or shocks to liquidity trading. Because of the information asymmetry between MMs and speculators, any noise-trading shock to asset $n$ affects its price $P_{1}(n)$ through its order flow $\omega_{1}(n)$. This shock, however, does not induce the speculators to revise their trading strategies in equilibrium, because they are unaware of it occurred. ${ }^{37}$ Nonetheless, if fundamental risks are correlated across countries $[\beta \neq O$ in Equation (1)], then the MMs deem the observed $d \omega_{1}(n)$ potentially revealing about other terminal payoffs $v(j)$ and speculators' portfolio rebalancing activity. This incorrect cross-inference eventually induces excess comovement $\left\{\right.$ e.g., $\left[\frac{\partial P_{1}(3)}{\partial z(1)}\right] \neq 0$ in Figure 4$\}$ for any possible $H$ or $K$.

Accordingly (and contrary to Propositions 2 and 3), the magnitude of this effect depends on the MMs' perceived intensity of adverse selection in trading, because it affects the magnitude of $\Lambda$ (Section 1.4) but not $d \omega_{1}$ (nor its informativeness). For instance, when $K$ increases, more informed trading in $\omega_{1}$ and more aggressive competition among speculators induce the MMs to make each market more liquid, thus ultimately reducing the impact of $d z(n)$ on $P_{1} \cdot{ }^{38}$ However, as in Section 2.2, a greater number of heterogeneously informed traders not only makes it easier for the MMs to learn the shared portion of their private signals from $\omega_{1}$ but also makes it more difficult for the MMs to learn the individual portions of those

\footnotetext{
${ }_{37} \overline{\text { In particular, }}, \frac{\partial X_{k}(j)}{\partial z(n)}=0$, so $d \omega_{1}(j)=0$.

${ }^{38}$ Indeed, $\lim _{K \rightarrow \infty} \frac{\partial P_{1}}{\partial z}=O$ because $\lim _{K \rightarrow \infty} \sqrt{K} \Lambda=O$.
} 


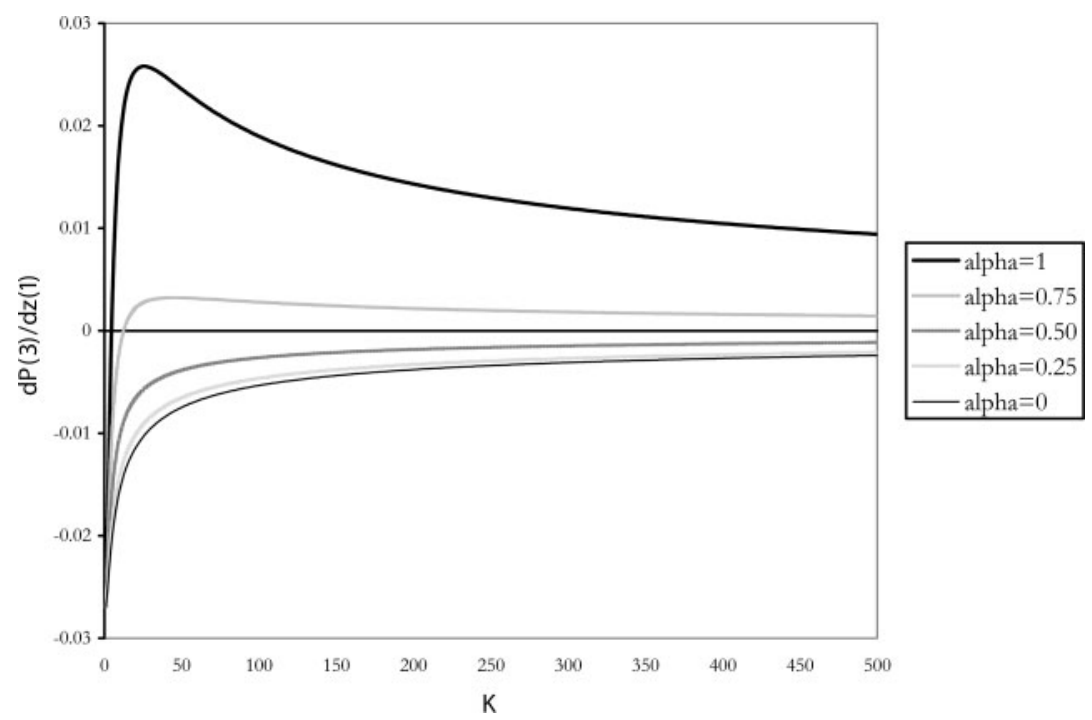

Figure 4

Three-country economy: contagion from noise-trading shocks

Figure 4 plots a measure of contagion from noise-trading shocks in the three-country economy of Equation (2), $\left[\frac{\partial P_{1}(3)}{\partial z(1)}\right]$ of Proposition 4, with respect to the number of better informed speculators $(K)$ in the three-country economy of Equation (2), as a function of the number of better informed speculators $(K)$, given its parametrization in Appendix B. I compute $\left[\frac{\partial P_{1}(3)}{\partial z(1)}\right]$ for different values of $\alpha$ in $\Sigma_{c}^{*}=\alpha \Sigma_{c}+(1-\alpha) \rho \Sigma_{\delta}$, that is, for different degrees of information heterogeneity.

signals. Indeed, $\left[\frac{\partial P_{1}(3)}{\partial z(1)}\right]$ in Figure 4 initially increases for greater $K$ when speculators are more heterogeneously informed ( $\alpha$ is high), because the second effect induces more incorrect cross-inference by the MMs, before eventually declining toward zero. Conversely, when speculators are more homogeneously informed ( $\alpha$ is low), only the first effect arises and the intensity of contagion converges monotonically to zero.

\section{A Block-Contagion Condition}

One of the most important features of the novel mechanism for the propagation of shocks across fundamentally unrelated markets described in Section 2 is the learning activity of the uninformed dealers. In the model of Section 1, the MMs rationally update their beliefs about the terminal payoffs of the traded assets from the observed order flow before setting equilibrium prices. Within this process, the structure of the economy of Equation (1) leads them to use the observed demand for one asset to learn about the terminal payoffs of other assets. This updating activity - previously labeled cross-inference - is crucial because it motivates 
the risk-neutral speculators to trade strategically across assets (as in the example of Section 2.1), rather than in each asset separately, to minimize the resulting dissipation of information. In the absence of cross-inference by the MMs, there would be no strategic portfolio rebalancing by the speculators, hence no financial contagion in that stylized economy.

I emphasized in Propositions 2 to 4 that in my model cross-inference can take place only if the real economy (i.e., the liquidation values $v$ ) is fundamentally interconnected $[\beta \neq O$ in Equation (1)], because otherwise the MMs would have no rational incentive to do so. This is, however, not equivalent to saying that in my setting excess comovement may occur only among fundamentally related assets. Section 2.1 showed in fact that, in the three-country economy of Equation (2), an idiosyncratic shock to country 1 may affect the equilibrium price of country 3's assets although $\operatorname{cov}[v(1), v(3)]=0$. The exposure of both "peripheral" countries 1 and 3 to the "center" country $2(\operatorname{cov}[v(1), v(2))>0]$ and $\operatorname{cov}[v(2), v(3))>0]$ through $\vartheta(1)$ and $\vartheta(2)$, respectively) is in fact sufficient to induce the MMs to cross-infer and the speculators to trade strategically. Contagion then ensues when the speculators' information is heterogeneous.

Consider instead the following economy:

$$
\begin{aligned}
& v(1)=u(1)+\vartheta(1) \\
& v(2)=u(2)+0.5 \vartheta(2) \\
& v(3)=u(3)+\vartheta(2) .
\end{aligned}
$$

In Equation (20), the two "peripheral" countries 1 and 3 are still fundamentally unrelated (i.e., $\operatorname{cov}[v(1), v(3)]=0$ ). Yet, now they do not share any exposure to the "core" market 2 (i.e., $\beta(2,1)=0$ ). In this setting, uninformed but rational MMs have no reason to use the observed order flow for country 1's assets to learn about the payoffs of countries 2 and 3 's assets. ${ }^{39}$ Hence, rational speculators would reap no benefit from trading strategically in those assets in response to an idiosyncratic shock to country 1 (e.g., $d u(1)<0$ ), so they do not. ${ }^{40}$ Then, contagion from country 1 to countries 2 and 3 cannot ensue. ${ }^{41}$

Nevertheless, Equation (20) does motivate the MMs to use order flow for country 2's assets to infer the terminal payoffs of country 3's assets, thus the speculators to trade strategically in both. Therefore, an idiosyncratic shock to country 2 may still propagate to the equilibrium price of

\footnotetext{
${ }^{39}$ For instance, $\Lambda(1,1)=0.251$ but $\Lambda(1,2)=\Lambda(1,3)=0$ if $K=15$ and $\alpha=1$.

${ }^{40}$ Indeed, $\frac{\partial X_{k}(2)}{\partial u(1)}=C \Sigma_{u} \Sigma_{S_{u}}^{-1}(2,1)=0$ and $\frac{\partial X_{k}(3)}{\partial u(1)}=C \Sigma_{u} \Sigma_{S_{u}}^{-1}(3,1)=0$ for any $K$ and $\alpha$.

${ }^{41}$ Consistently, according to Kaminsky, Reinhart, and Vegh (2003, p. 52), "It is of no surprise that a domestic crisis ... in countries that are approximately autarkic [such as country 1 in Eq. (20)] ... will not likely have immediate repercussions in world capital markets.”
} 
country 3's assets if speculators are heterogeneously informed. ${ }^{42}$ Equivalently, financial contagion between countries 2 and 3 (as characterized in Definition 2) may still occur in the economy of Equation (20). The following proposition generalizes the above intuition to the setting of Equation (1).

Proposition 5. If $\Sigma_{v}$ is block-diagonal, then there may be financial contagion across assets within a block but not among blocks of assets. ${ }^{43}$

In Section 1, I designed a stylized model in which various channels of financial contagion already explored by the literature (correlated information, correlated liquidity, and portfolio rebalancing) have been ruled out by construction. Within this framework, when underlying block-economies are not fundamentally interconnected, the order flow in one block of securities cannot reveal any information about the terminal payoffs of other blocks of securities. In those cases-Proposition 5 states-neither cross-inference is possible in the MMs' belief updating process nor speculators' strategic portfolio diversification is effective in limiting the informativeness of the order flow. Hence, financial contagion cannot occur among those blocks.

This result suggests that the trend toward a more integrated world economy, by magnifying the significance of global factors in explaining local and regional returns [e.g., Bekaert, Harvey, and Ng (2005)] and so providing a motivation for cross-inference (a neither diagonal nor block-diagonal $\Sigma_{v}$ ), might have increased the likelihood of contagion among international financial markets. Indeed, the importance of shared macroeconomic exposures [e.g., as in Equation (2)] for the contagion mechanism described in Propositions 2 to 4 is consistent with extant evidence that many recent episodes of financial turmoil spread across fundamentally unrelated peripheral countries through their impact on financial centers [e.g., Kaminsky and Reinhart (2000b), and references therein].

Proposition 5 also suggests that excess comovement among securities within the same asset classes may be larger and more likely than across asset classes [e.g., as in Equation (20)]. This implication finds support in several studies of the patterns of stock and bond return comovements in proximity of financial crises, such as Kaminsky and Schmukler (2002), Rigobon (2002), Kaminsky, Reinhart, and Vegh (2003), and Bekaert, Harvey, and Ng (2005). For instance, Bekaert, Harvey, and Ng (2005) estimated a significantly greater

\footnotetext{
${ }^{42} \overline{\text { For example, }}, \frac{\partial X_{k}(3)}{\partial u(2)}=C \Sigma_{u} \Sigma_{S_{u}}^{-1}(3,2)=-0.041$ and, eventually, $\frac{\partial P(3)}{\partial u(2)}=-0.204$ if $K=15$ and $\alpha=1$.

${ }^{43}$ This result is similar to Proposition 3 in Kodres and Pritsker (2002). Yet, in their setting, a block-diagonal fundamental covariance matrix prevents portfolio rebalancing due to risk considerations from inducing excess comovement among fundamentally unrelated blocks. Risk-neutrality prevents that channel of contagion from operating in our model.
} 
extent of regional contagion (i.e., within Asia, Europe, and Latin America) than of global contagion during the crises in both Mexico and East Asia in the 1990s.

\section{Conclusions}

There is growing empirical evidence that comovement of asset prices within and across domestic and international financial markets is often excessive, that is, cannot be justified by economic fundamentals. The main motivation of this study was to investigate why financial contagion has been occurring with increasing frequency and magnitude, especially for emerging markets.

It is often argued that greater price and return comovements [e.g., Bekaert and Harvey (2000)] and the recurrence of crises and contagion events [e.g., Bordo et al. (2000)] should be attributed to the intensification of capital mobility and financial integration across world capital markets, in particular [as in Kodres and Pritsker (2002)] when this process is accompanied by persistent information asymmetries among market participants. It is nonetheless difficult to believe that the increased interest of institutional investors in emerging markets, spurred by recent liberalization measures, would have led to higher (not lower) information asymmetry, hence increasing (not decreasing) their vulnerability to contagion.

I claimed instead that economic and financial integration, by making the world economy more interconnected and increasing investors' interest in emerging markets, may have raised their vulnerability to financial contagion from real shocks if those investors share private information about these markets asymmetrically. Significant differences in private information among imperfectly competitive traders are indeed more likely in the smaller, less mature, and regulated financial markets of developing economies where the process of generation, acquisition, and dissemination of information is still insufficiently standardized, and large speculators can still affect market prices. My analysis further indicated that disparities in the degree of information heterogeneity across countries may explain why contagion occurs more often and with greater extent in some markets than in others.

Is globalization at least partially responsible for the contagion events sweeping several developing economies in the recent past? The process of economic and financial integration has taken place only in the last two decades and is still at an early stage in many countries. Sophisticated speculators investing in emerging capital markets are still relatively less numerous, and the information they produce (or receive) and use for trading is still more heterogeneous than in the more mature markets of developed economies. According to my model, these facts currently justify a high, even rising vulnerability of the global financial 
system to contagion among fundamentally unrelated emerging markets. Yet, the trend for greater participation of institutional investors to those markets and the adoption of uniform, more stringent rules for the production and disclosure of corporate and macroeconomic information may eventually lead to greater competition and less information asymmetry and heterogeneity among traders, hence potentially reducing such vulnerability.

\section{Appendix A}

Definition A1. (Greene, 1997, p. 32) A matrix A is block-diagonal if it can be represented as a partitioned matrix where all the off-diagonal submatrices are null matrices.

Definition A2. (Greene, 1997, p. 46) If $A$ is a real matrix and the quadratic form $q=x^{\prime} A x>0$ for all real nonzero vectors $x$, the matrix $A$ is positive definite. If the matrix $A$ is also symmetric, then $A$ is $S P D$.

Theorem A1. (Bellman, 1970, pp. 54 and 91) A necessary and sufficient condition that the matrix $A$ be positive definite is that all the characteristic roots of $A$ be positive. Therefore, a positive definite matrix $A$ is always nonsingular. If the matrix $A$ is $S P D$, so is $A^{-1}$.

Proof of Proposition 1. The proof is by construction: (i) I specify general linear functionals for the pricing rule and speculators' demands,

$$
\begin{aligned}
& P_{1}\left(\omega_{1}\right)=A_{0}+A_{1} \omega_{1}, \\
& X_{k}\left(\delta_{k}\right)=B_{0}+B_{1} \delta_{k},
\end{aligned}
$$

where the matrix $A_{1}$ is SPD and the matrix $B_{1}$ is nonsingular, and (ii) I then show that those functionals indeed represent a rational expectations equilibrium when their parameters are the ones in Equations (9) and (10). The details of the proof are similar to those in Caballé and Krishnan (1994, Proposition 3.1) and are omitted. I only need to prove that the matrix $\Gamma$, defined as

$$
\Gamma=2\left[\Sigma_{\delta}-(K-1) H \Sigma_{c}\right]\left[H^{-1}+(K-1)\left(\Sigma_{\delta}^{-1} \Sigma_{c}-\Sigma_{c} \Sigma_{\delta}^{-1}\right)\right]^{-1},
$$

is SPD for any $N \times F$ matrix $\beta$ in the economy of Equation (1). The matrix $\Gamma$ is SPD by the Rayleigh's principle [e.g., Bodewig (1959, p. 283)] and Theorem A1, because the distributional assumptions in Section 1 imply that so are the matrices $\Sigma_{c}$ [Equation (5)] and $\Sigma_{\delta}^{-1} \Sigma_{c} \Sigma_{\delta}^{-1}$.

Proof of Remark 1. The statement of the remark follows from the definitions of $H$ and $\Lambda$ in Proposition 1 and the observation that, when $K>1$ and speculators receive the same or similar set of signals, the matrix $\Sigma_{c}$ [Equation (5)] is equal to $\Sigma_{\delta}$ [Equation (4)] or $\rho \Sigma_{\delta}$, respectively.

Proof of Proposition 2. Equations (15) and (16) ensue from Proposition 1, given the definitions of $S_{u k}$ and $S_{\vartheta k}$ and that $\delta_{k}=\Sigma_{u} \Sigma_{S_{u}}^{-1}\left(S_{u k}-\bar{u}\right)+\beta \Sigma_{\vartheta} \Sigma_{S_{\vartheta}}^{-1}\left(S_{\vartheta k}-\bar{\vartheta}\right)$ for all 
$k=1, \ldots, K$. In Section 1, I assumed that all liquidity and information noise shocks are independent across assets, that is, that the matrices $\Sigma_{z}, \Sigma_{\varepsilon_{u}}$, and $\Sigma_{\varepsilon_{\vartheta}}$ are diagonal. When $\beta=O$, the matrix $\Sigma_{v}$ is also diagonal. Hence, it is straightforward to show that the matrices $\Sigma_{\delta}$ [Equation (4)] and $\Sigma_{c}$ [Equation (5)] are diagonal as well. All their sums, products, and inverses are therefore diagonal and so are the matrices $\Lambda, C$, and $H$. The no-contagion result then ensues from Definition 2 and inspection of Equations (15) and (16) in Proposition 2. When $\beta \neq O$ and either $K=1$ or $H=\left[\frac{1}{2+\rho(K-1)}\right] I$, inspection of $K H \Sigma_{u} \Sigma_{S_{u}}^{-1}$ and $K H \beta \Sigma_{\vartheta} \Sigma_{S_{\vartheta}}^{-1}$ immediately reveals that $\left[\frac{\partial P_{1}(n)}{\partial u(j)}\right]=0$ and $\left[\frac{\partial P_{1}(n)}{\partial \vartheta(f)}\right]=0$ (if $\beta(n, f)=0)$ for any $n, j=1, \ldots, N, n \neq j$, and for any $f=1, \ldots, F$. When $\beta \neq O, K>1$, and $\Sigma_{c} \neq \rho \Sigma_{\delta}$ (i.e., when $H \neq \frac{1}{2+\rho(K-1)} I$ ), the matrix $H$ is instead nondiagonal, hence so are $K H \Sigma_{u} \Sigma_{S_{u}}^{-1}$ and $K H \beta \Sigma_{\vartheta} \Sigma_{S_{\vartheta}}^{-1}$. In this case, the absolute magnitude of contagion, as measured by $\left|\frac{\partial P_{1}(n)}{\partial u(j)}\right|$ and $\left|\frac{\partial P_{1}(n)}{\partial \vartheta(f)}\right|$, is increasing in $K$ and $\alpha$ because so is each positive element of the matrix $|K H|=\left|\left(\frac{2}{K} I+\frac{K-1}{K} \Sigma_{c}^{*} \Sigma_{\delta}^{-1}\right)^{-1}\right|$. The latter stems from (i) $\left|\Sigma_{u} \Sigma_{S_{u}}^{-1}(n, j)\right| \leq \rho I(n, j)$ and $\left|\Sigma_{\vartheta} \Sigma_{S_{\vartheta}}^{-1}(n, j)\right| \leq \rho I(n, j)$ for any $\rho \in(0,1]$ and for each $n, j=1, \ldots, N$ (with a strict inequality holding for at least each $n=j$ ) implying that $\left|\Sigma_{c}^{*} \Sigma_{\delta}^{-1}(n, j)\right| \leq \rho I(n, j)$ for any $\rho \in(0,1]$ and for each $n, j=1, \ldots, N$ (with a strict inequality holding for at least each $n=j$ ), (ii) $\frac{\partial \frac{1}{\partial K}}{\partial K}=-\frac{1}{K^{2}}<0$, and (iii) $\frac{\partial \frac{K-1}{K K}}{\partial K}=\frac{1}{K^{2}}>0$. Finally, Equations (15) and (16) do not depend on the intensity of liquidity trading, for the matrices $H, \Sigma_{u}, \Sigma_{s_{u}}, \Sigma_{\vartheta}, \Sigma_{s_{\theta}}$, and $\beta$ do not depend on $\Sigma_{z}$.

Proof of Proposition 3. The statement of the proposition follows from Proposition 1, the proof of Proposition 2, and the definitions of $S_{u k}, S_{\vartheta k}, \delta_{k}$, and $H$, which also imply that both $\frac{\partial P_{1}}{\partial u^{\prime}}=\frac{\partial P_{1}}{\partial \varepsilon_{u k^{\prime}}}$ and $\frac{\partial P_{1}}{\partial \vartheta^{\prime}}=\frac{\partial P_{1}}{\partial \varepsilon_{\vartheta k^{\prime}}}$, when $K=1$.

Proof of Proposition 4. Equation (19) follows from Equation (9) in Proposition 1. Remark 1, Definition 2, and the fact that $\Lambda$ is nondiagonal (unless $\beta=O$ ) then ensure that the existence of contagion induced by shocks to $z$ does not depend on $K$ or $H$.

Proof of Proposition 5. In Section 1, I assumed that all liquidity and information noise shocks are independent across assets, that is, that the matrices $\Sigma_{z}, \Sigma_{\varepsilon_{u}}$, and $\Sigma_{\varepsilon_{\vartheta}}$ are diagonal. Hence, if the matrix $\Sigma_{v}$ is block-diagonal, then it is straightforward to show that the matrices $\Sigma_{\delta}$ [Equation (4)] and $\Sigma_{c}$ [Equation (5)] are block-diagonal as well. All their sums, products, and inverses are therefore block-diagonal and so are the matrices $\Lambda, C$, and $H$. The block-contagion result then ensues from Definition 2 and inspection of Equations (15) to (19) in Propositions 2 to 4.

\section{Appendix B}

$$
\begin{gathered}
\Sigma_{u}=\left[\begin{array}{ccc}
1 & 0 & 0 \\
0 & 0.25 & 0 \\
0 & 0 & 1
\end{array}\right], \quad \Sigma_{\vartheta}=\left[\begin{array}{ll}
3 & 0 \\
0 & 1
\end{array}\right], \\
\Sigma_{\varepsilon_{u}}=\left[\begin{array}{lll}
2 & 0 & 0 \\
0 & 2 & 0 \\
0 & 0 & 2
\end{array}\right], \quad \Sigma_{\varepsilon_{\vartheta}}=\left[\begin{array}{cc}
0.25 & 0 \\
0 & 0.25
\end{array}\right], \quad \Sigma_{z}=\left[\begin{array}{lll}
1 & 0 & 0 \\
0 & 1 & 0 \\
0 & 0 & 1
\end{array}\right] .
\end{gathered}
$$




\section{References}

Admati, A., 1985, "A Noisy Rational Expectations Equilibrium for Multi-Asset Securities Markets," Econometrica, 53, 629-657.

Admati, A., and P. Pfleiderer, 1988, "A Theory of Intraday Trading Patterns: Volume and Price Variability,” Review of Financial Studies, 1, 3-40.

Back, K., H. Cao, and G. Willard, 2000, “Imperfect Competition Among Informed Traders," Journal of Finance, 55, 2117-2155.

Backus, D., D. Kehoe, and F. Kydland, 1992, "International Real Business Cycles,” Journal of Political Economy, 100, 745-775.

Baig, T., and I. Goldfajn, 1999, "Financial Market Contagion in the Asian Crisis," IMF Staff Papers, 46, $167-195$.

Barberis, N., A. Shleifer, and J. Wurgler, 2005, “Comovement,” Journal of Financial Economics, 75, 283-317.

Baxter, M., and M. Crucini, 1993, "Explaining Saving-Investment Correlations," American Economic Review, 83, 416-436.

Bekaert, G., and C. Harvey, 2000, "Foreign Speculators and Emerging Equity Markets," Journal of Finance, 55, 565-613.

Bekaert, G., C. Harvey, and R. Lumsdaine, 2002, "Dating the Integration of World Equity Markets," Journal of Financial Economics, 65, 203-247.

Bekaert, G., C. Harvey, and A. Ng, 2005, "Market Integration and Contagion," Journal of Business, 75, 39-69.

Bellman, R., 1970, Introduction to Matrix Analysis, McGraw-Hill, New York.

Bhattacharyya, S., and V. Nanda, 1999, "Marking to Market and the Closed-End Fund Discount," Working Paper, Ross School of Business, University of Michigan.

Bodewig, E., 1959, Matrix Calculus, North-Holland, Amsterdam, The Netherlands.

Bordo, M., B. Eichengreen, D. Klingebiel, and M. Soledad, 2000, "Is the Crisis Problem Growing More Severe?" Working Paper, Rutgers University.

Borensztein, E., and G. Gelos, 2000, "A Panic-Prone Pack? The Behavior of Emerging Market Mutual Funds,” Working Paper 00/198, IMF.

Bowden, R., and V. Martin, 1995, "International Business Cycles and Financial Integration," Review of Economics and Statistics, 77, 305-320.

Boyer, B., T. Kumagai, and K. Yuan, 2002, "How Do Crises Spread? Evidence from Accessible and Inaccessible Stock Indices," Working Paper, Ross School of Business, University of Michigan; forthcoming in Journal of Finance.

Brennan, M., and H. Cao, 1997, "International Portfolio Investment Flows," Journal of Finance, 52, $1851-1880$.

Brown, S., W. Goetzmann, and J. Park, 1998, "Hedge Funds and the Asian Currency Crisis of 1997," Working Paper 6427, NBER.

Caballé, J., and M. Krishnan, 1994, "Imperfect Competition in a Multi-Security Market with Risk Neutrality," Econometrica, 62, 695-704.

Calvo, G., 1999, "Contagion in Emerging Markets: When Wall Street is a Carrier," Working Paper, University of Maryland.

Calvo, G., and E. Mendoza, 2000, "Capital-Market Crises and Economic Collapse in Emerging Markets: An Informational-Frictions Approach," American Economic Review, 90, 59-64. 
Cass, D., and A. Pavlova, 2004, “On Trees and Logs," Journal of Economic Theory, 116, 41-83.

Chuhan, P., 1992, "Sources of Portfolio Investments in Emerging Markets," Working Paper, World Bank.

Claessens, S., S. Djankov, and L. Lang, 2000, "Separation of Ownership and Control in East Asian Countries," Journal of Financial Economics, 58, 81-112.

Cochrane, J., F. Longstaff, and P. Santa-Clara, 2003, "Two Trees: Asset Price Dynamics Induced by Market Clearing," Working Paper, University of Chicago.

Cole, H., and M. Obstfeld, 1991, "Commodity Trade and International Risk Sharing," Journal of Monetary Economics, 28, 3-24.

Connolly, R., and A. Wang, 2000, "On Stock Market Return Co-movements: Macroeconomic News, Dispersion of Beliefs, and Contagion,” Working Paper, University of North Carolina at Chapel Hill.

Corsetti, G., M. Pericoli, and M. Sbracia, 2002, "Some Contagion, Some Interdependence: More Pitfalls in Tests of Financial Contagion," Discussion Paper 3310, CEPR.

Das, S., and R. Sundaram, 2002, "Fee Speech: Signalling, Risk-Sharing, and the Impact of Fee Structures on Investor Welfare," Review of Financial Studies, 15, 1465-1497.

Diamond, D., and R. Verrecchia, 1981, "Information Aggregation in a Noisy Rational Expectations Economy," Journal of Financial Economics, 9, 221-235.

Diether, K., C. Malloy, and A. Scherbina, 2002, "Differences of Opinion and the Cross Section of Stock Returns," Journal of Finance, 57, 2113-2141.

Disyatat, P., and G. Gelos, 2001, “The Asset Allocation of Emerging Market Mutual Funds,” Working Paper 01/111, IMF.

Edwards, F., 1999, "Hedge Funds and the Collapse of Long-Term Capital Management," Journal of Economic Perspectives, 13, 189-210.

Eichengreen, B., and D. Mathieson, 1998, "Hedge Funds and Financial Market Dynamics," Occasional Paper 166, IMF.

Feldstein, M., and C. Horioka, 1980, "Domestic Saving and International Capital Flow,” Economic Journal, 90, 314-329.

Fleming, J., C. Kirby, and B. Ostdiek, 1998, "Information and Volatility Linkages in the Stock, Bond, and Money Markets," Journal of Financial Economics, 49, 111-137.

Forbes, K., and R. Rigobon, 2002, "No Contagion, Only Interdependence: Measuring Stock Market CoMovements," Journal of Finance, 57, 2223-2261.

Foster, F., and S. Viswanathan, 1996, "Strategic Trading When Agents Forecast the Forecasts of Others," Journal of Finance, 51, 1437-1478.

Frankel, J., and S. Schmukler, 1996, "Country Fund Discount and the Mexican Crisis of December 1994: Did Local Residents Turn Pessimistic Before International Investors?” Open Economies Review, 7, 534-551.

Froot, K., D. Scharfstein, and J. Stein, 1992, "Herd on the Street: Informational Inefficiencies in a Market with Short-Term Speculation,” Journal of Finance, 47, 1461-1484.

Froot, K., P. O'Connell, and M. Seasholes, 2001, "The Portfolio Flows of International Investors," Journal of Financial Economics, 59, 151-193.

Greene, W., 1997, Econometric Analysis, Prentice Hall, Englewood Cliffs, NJ.

Grinblatt, M., and S. Ross, 1985, "Market Power in a Securities Market with Endogenous Information," Quarterly Journal of Economics, 100, 1143-1167. 
Helpman, E., and A. Razin, 1978, A Theory of International Trade Under Uncertainty, Academic Press, New York.

Holden, G., and A. Subrahmanyam, 1992, "Long-Lived Private Information and Imperfect Competition," Journal of Finance, 47, 247-270.

Kallberg, J., C. Liu, and P. Pasquariello, 2002, "Regime Shifts in Asian Equity and Real Estate Markets," Real Estate Economics, 30, 263-291.

Kallberg, J., C. Liu, and P. Pasquariello, 2005, "An Examination of the Asian Crisis: Regime Shifts in Currency and Equity Markets,” Journal of Business, 78, 169-211.

Kallberg, J., and P. Pasquariello, 2004, "Time-Series and Cross-Sectional Excess Comovement in Stock Indexes," Working Paper, Ross School of Business, University of Michigan.

Kaminsky, G., R. Lyons, and S. Schmukler, 2000, "Managers, Investors, and Crises: Mutual Fund Strategies in Emerging Markets,” Working Paper 7855, NBER.

Kaminsky, G., R. Lyons, and S. Schmukler, 2001, "Mutual Fund Investment in Emerging Markets: An Overview," Working Paper, George Washington University.

Kaminsky, G., and C. Reinhart, 2000a, "On Crises, Contagion, and Confusion,” Journal of International Economics, 51, 145-168.

Kaminsky, G., and C. Reinhart, 2000b, "The Center and the Periphery: Tales of Financial Turmoil," Working Paper, George Washington University.

Kaminsky, G., C. Reinhart, and C. Vegh, 2003, "The Unholy Trinity of Financial Contagion,” Journal of Economic Perspectives, 17, 51-74.

Kaminsky, G., and S. Schmukler, 2002, "Emerging Market Instability: Do Sovereign Ratings Affect Country Risk and Stock Returns?” Working Paper, George Washington University.

Karolyi, G., and R. Stulz, 1996, "Why Do Markets Move Together? An Investigation of U.S.-Japan Stock Return Comovements," Journal of Finance, 51, 951-986.

Kim, W., and S. Wei, 2002, "Foreign Portfolio Investors Before and During a Crisis," Journal of International Economics, 56, 77-96.

King, M., and S. Wadhwani, 1990, "Transmission of Volatility Between Stock Markets," Review of Financial Studies, 3, 5-33.

King, M., E., Sentana, and S. Wadhwani, 1994, "Volatility and Links Between National Stock Markets," Econometrica, 62, 901-934.

Kodres, L., and M. Pritsker, 2002, “A Rational Expectations Model of Financial Contagion,” Journal of Finance, 57, 769-799.

Kyle, A., 1985, “Continuous Auctions and Insider Trading,” Econometrica, 53, 1315-1335.

Kyle, A., 1989, "Informed Speculation with Imperfect Competition," Review of Economic Studies, 56, 317-355.

Kyle, A., and W. Xiong, 2001, "Contagion as a Wealth Effect," Journal of Finance, 56, 1401-1440.

Maddala, G., 1987, Econometrics, McGraw-Hill, New York.

Mody, A., and M. Taylor, 2002, "Common Vulnerabilities," Working Paper, IMF.

Nanda, V., M. Narayanan, and V. Warther, 2000, "Liquidity, Investment Ability, and Mutual Fund Structure," Journal of Financial Economics, 57, 417-443.

Pasquariello, P., 2005, “Are Financial Crises Indeed 'Crises?' Evidence from the Emerging ADR Market," Working Paper, Ross School of Business, University of Michigan. 
Pavlova, A., and R. Rigobon, 2004, “Asset Prices and Exchange Rates,” Working Paper, MIT.

Pindyck, R., and J. Rotemberg, 1990, “The Excess Co-Movement of Commodity Prices," Economic Journal, 100, 1173-1189.

Pindyck, R., and J. Rotemberg, 1993, “The Comovement of Stock Prices,” Quarterly Journal of Economics, 108, 1073-1104.

Rigobon, R., 2002, “The Curse of Non-investment Grade Countries,” Journal of Development Economics, $69,423-449$.

Seasholes, M., 2000, "Smart Foreign Traders in Emerging Markets,” Working Paper, Harvard University.

Shiller, R., 1989, "Comovements in Stock Prices and Comovements in Dividends," Journal of Finance, 44, 719-729.

Yuan, K., 2005, "Asymmetric Price Movements and Borrowing Constraints: A REE Model of Crisis, Contagion, and Confusion,” Journal of Finance, 60, 379-411.

Zapatero, F., 1995, "Equilibrium Asset Prices and Exchange Rates," Journal of Economic Dynamics and Control, 19, 787-811. 